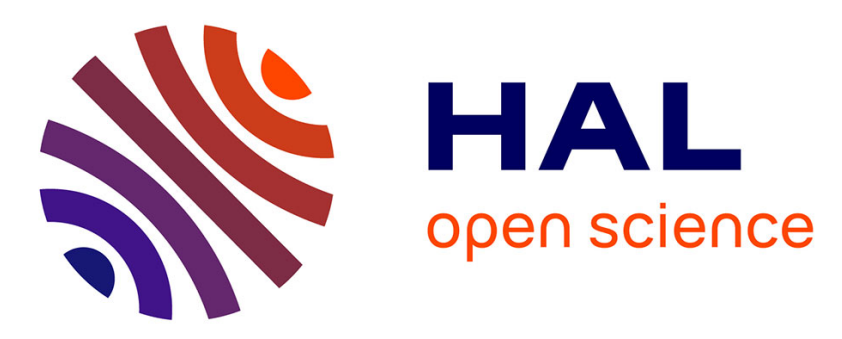

\title{
Detailed Product Analysis during Low- and Intermediate-Temperature Oxidation of Ethylcyclohexane
}

Benoit Husson, Olivier Herbinet, Pierre Alexandre Glaude, Syed Sayeed Ahmed, Frédérique Battin-Leclerc

\section{To cite this version:}

Benoit Husson, Olivier Herbinet, Pierre Alexandre Glaude, Syed Sayeed Ahmed, Frédérique BattinLeclerc. Detailed Product Analysis during Low- and Intermediate-Temperature Oxidation of Ethylcyclohexane. Journal of Physical Chemistry A, 2012, 116 (21), pp.5100-5111. 10.1021/jp301043r . hal-00726377

\section{HAL Id: hal-00726377 \\ https://hal.science/hal-00726377}

Submitted on 30 Aug 2012

HAL is a multi-disciplinary open access archive for the deposit and dissemination of scientific research documents, whether they are published or not. The documents may come from teaching and research institutions in France or abroad, or from public or private research centers.
L'archive ouverte pluridisciplinaire HAL, est destinée au dépôt et à la diffusion de documents scientifiques de niveau recherche, publiés ou non, émanant des établissements d'enseignement et de recherche français ou étrangers, des laboratoires publics ou privés. 


\title{
Detailed Product Analysis during Low- and Intermediate- Temperature Oxidation of Ethylcyclohexane
}

\author{
B. Husson ${ }^{\dagger}$, O. Herbinet ${ }^{\dagger}$, P. A. Glaude ${ }^{\dagger}$, S. S. Ahmed ${ }^{\ddagger}$, and F. Battin-Leclerc ${ }^{* \dagger}$ \\ ${ }^{\dagger}$ Laboratoire Réactions et Génie des Procédés, CNRS, Université de Lorraine, 1 Rue Grandville, BP \\ 20451, 54001 NANCY Cedex, France \\ ${ }^{\ddagger}$ Saudi-Aramco Research \& Development Center, Dhahran 31311, Saudi Arabia
}

\begin{abstract}
An experimental study of the oxidation of ethylcyclohexane has been performed in a jet-stirred reactor with online gas chromatography, under quasi-atmospheric pressure (800 Torr), at temperatures ranging from 500 to $1100 \mathrm{~K}$ (low- and intermediate-temperature zone including the negative temperature coefficient area), at a residence time of $2 \mathrm{~s}$, and for three equivalence ratios $(0.25,1$, and 2). Ethylcyclohexane displays important low-temperature reactivity with a well-marked negative temperature coefficient behavior. In addition to 47 products with a mass lower than ethylcyclohexane which have been quantified, many species with a $\mathrm{C}_{8} \mathrm{H}_{14} \mathrm{O}$ formula (molecular weight of 126) were detected by GC-MS and 7 of them were quantified. These molecules are cyclic ethers, ketones, and aldehydes with the same carbon skeleton as the reactant. Experiments were also carried on under the same conditions for two other $C_{8}$ hydrocarbons, $n$-octane and 1-octene, showing that the reactivity of ethylcyclohexane is close to that of the alkene and lower than that of the alkane. Simulations using a detailed kinetic model of the literature allow a good prediction of the global reactivity and of the main hydrocarbon products for temperatures above $800 \mathrm{~K}$. The main reaction channels leading to the observed reaction products at both low (below $800 \mathrm{~K}$ ) and intermediate temperature (above $800 \mathrm{~K}$ ) are discussed.
\end{abstract}

\section{Corresponding Author:}

Frédérique Battin-Leclerc

Laboratoire Réactions et Génie des Procédés

Ecole Nationale Supérieure des Industries Chimiques

BP 20451, 1 rue Grandville, 54000 Nancy, France

Tel: +33 (0)3 83175125

Fax: +33 (0)3 83178120

E-mail: Frederique.Battin-Leclerc@ensic.inpl-nancy.fr 


\section{Introduction}

The $n$-alkylated cyclohexanes are a homologous series of hydrocarbon compounds that are commonly present in crude oil and refinery products such as diesel fuels (1). The components of diesel fuels have a number of atoms of carbon which ranges approximately from 10 to 22 with an average around 14 and can be classified into the following chemical families: $n$-alkanes, iso-alkanes, aromatics, and cycloalkanes (2). Cycloalkanes are usually present less than $5 \%$ in diesel fuel derived from conventional crude-oil sources but are much more abundant in alternative diesel fuel derived from oil-sand deposits. These species typically have one ring with multiple alkyl side chains, e.g., alkylcyclohexanes (3).

The literature is relatively rich in detailed kinetic models for combustion of alkanes (e.g., refs 4-7) and recently alkyl-aromatics (e.g., refs 8-10). However, there are fewer studies on the other classes of molecules including alkylcyclohexanes, and the mechanisms involved in their combustion are poorly known.

Table 1 summarizes previous experimental studies of the oxidation of cyclohexane and alkylcyclohexanes. Although a fair number of studies have already been performed on the oxidation of cyclohexane and methylcyclohexane in different experimental apparatuses, very little information is available on the oxidation of alkylcyclohexanes with a larger alkylic chain. Moreover, studies performed on cyclohexane and $n$-propylcyclohexane oxidation in a jet-stirred reactor enclosed no information about their low-temperature reactivity.

Table 1. Summary of the studies about the oxidation of cyclohexane and alkyl-cyclohexanes

\begin{tabular}{|c|c|c|c|c|c|}
\hline Compounds & Reactor $^{d}$ & $\mathbf{T}(\mathbf{K})$ & P (bar) & $\phi$ & References \\
\hline \multirow{16}{*}{ Cyclohexane } & BR & $533-633$ & $0.1-0.3$ & $4.5-18$ & (Erreur! Source du renvoi \\
\hline & & $533-633$ & $0.1-0.3$ & 9 & \multirow{4}{*}{$\begin{array}{l}\text { (Erreur ! Source du renvoi } \\
\text { (Erreur ! Source du renvoi } \\
\text { (Erreur ! Source du renvoi } \\
\text { (Erreur ! Source du renvoi }\end{array}$} \\
\hline & & $673-783$ & $0.02-0.7$ & in $\mathrm{H}_{2} / \mathrm{O}_{2}$ & \\
\hline & & 635 & 0.06 & 9 & \\
\hline & JSR & $750-1200$ & $1-10$ & $0.5-1.5$ & \\
\hline & \multirow[t]{2}{*}{$\mathrm{RCM}$} & $600-900$ & $7-14$ & 1 & \multirow{11}{*}{$\begin{array}{l}\text { (Erreur ! Source du renvoi } \\
\text { (Erreur ! Source du renvoi } \\
\text { (Erreur ! Source du renvoi } \\
\text { (Erreur ! Source du renvoi } \\
\text { (Erreur ! Source du renvoi } \\
\text { (Erreur ! Source du renvoi } \\
\text { (Erreur ! Source du renvoi } \\
\text { (Erreur ! Source du renvoi } \\
\text { (Erreur ! Source du renvoi } \\
\text { (Erreur ! Source du renvoi } \\
\text { (Erreur! Source du renvoi }\end{array}$} \\
\hline & & 827 & 41.6 & 0.4 & \\
\hline & \multirow[t]{3}{*}{ ST } & $1280-1840$ & 7.3-9.5 & $0.5-2$ & \\
\hline & & $847-1379$ & $11-61$ & $0.25-1$ & \\
\hline & & $1280-1480$ & $1.5-3$ & $0.5-1$ & \\
\hline & \multirow[t]{2}{*}{ Motor } & $1000-1050$ & - & 9 & \\
\hline & & $750-860$ & $10-25$ & 0.25 & \\
\hline & \multirow[t]{2}{*}{ Flame $^{a}$} & - & 0.04 & 1 & \\
\hline & & - & 1 & 2.33 & \\
\hline & Flame $^{\mathrm{b}}$ & 353 & $1-20$ & $0.7-1.5$ & \\
\hline & Flame $^{c}$ & - & 1 & - & \\
\hline \multirow{10}{*}{ Methylcyclohexane } & \multirow{3}{*}{$\begin{array}{c}\mathrm{FR} \\
\mathrm{RCM}\end{array}$} & $1050-1200$ & 1 & 1 & \multirow{10}{*}{$\begin{array}{l}\text { (Erreur ! Source du renvoi } \\
\text { (Erreur ! Source du renvoi } \\
\text { (Erreur! Source du renvoi } \\
\text { (Erreur! Source du renvoi } \\
\text { (Erreur! Source du renvoi } \\
\text { (Erreur! Source du renvoi } \\
\text { (Erreur ! Source du renvoi } \\
\text { (Erreur! Source du renvoi } \\
\text { (Erreur! Source du renvoi } \\
\text { (Erreur! Source du renvoi }\end{array}$} \\
\hline & & 827 & 41.6 & 0.4 & \\
\hline & & $680-980$ & $10-20$ & 1 & \\
\hline & \multirow[t]{4}{*}{ ST } & $1250-2100$ & $1-4$ & $0.5-2$ & \\
\hline & & $795-1560$ & $1-50$ & $0.5-2$ & \\
\hline & & $881-1319$ & $10.8-69.5$ & $0.25-1$ & \\
\hline & & $1280-1480$ & $1.5-3$ & $0.5-1$ & \\
\hline & Motor & $750-860$ & $10-25$ & 0.25 & \\
\hline & Flame $^{a}$ & - & $0.02-0.04$ & 1-1.9 & \\
\hline & Flame $^{\mathrm{b}}$ & 353 & $1-20$ & $0.7-1.5$ & \\
\hline
\end{tabular}


Table 1. Continued

\begin{tabular}{|c|c|c|c|c|c|}
\hline Ethylcyclohexane & $\begin{array}{c}\text { ST } \\
\text { Flame }^{b}\end{array}$ & $\begin{array}{c}881-1319 \\
353\end{array}$ & $\begin{array}{c}10.8-69.5 \\
1-10\end{array}$ & $0.7-1.5$ & $\begin{array}{l}\text { (Erreur ! Source du renvoi } \\
\text { (Erreur ! Source du renvoi }\end{array}$ \\
\hline $\begin{array}{l}n \text {-Propyl } \\
\text { cyclohexane }\end{array}$ & $\begin{array}{c}\text { RCM } \\
\text { Flame }^{\mathrm{a}} \\
\text { Flame }^{\mathrm{b}}\end{array}$ & $\begin{array}{c}873-1033 \\
950-1250 \\
800-1400 \\
620-930 \\
- \\
353 \\
\end{array}$ & $\begin{array}{c}1 \\
1 \\
1-10 \\
0.45-1.34 \\
0.07 \\
1 \\
\end{array}$ & $\begin{array}{c}0.2-1.5 \\
0.5-1.5 \\
0.5-2 \\
0.3-0.5 \\
0.68 \\
0.7-1.5\end{array}$ & $\begin{array}{l}\text { (Erreur ! Source du renvoi } \\
\text { (Erreur ! Source du renvoi } \\
\text { (Erreur ! Source du renvoi } \\
\text { (Erreur ! Source du renvoi } \\
\text { (Erreur ! Source du renvoi } \\
\text { (Erreur ! Source du renvoi }\end{array}$ \\
\hline $\begin{array}{l}n \text {-butyl } \\
\text { cyclohexane }\end{array}$ & $\begin{array}{c}\text { FR } \\
\text { ST } \\
\text { Flame }\end{array}$ & $\begin{array}{c}600-820 \\
1280-1480 \\
353\end{array}$ & $\begin{array}{c}8 \\
1.5-3 \\
1\end{array}$ & $\begin{array}{c}0.38 \\
0.5-1 \\
0.7-1.5\end{array}$ & $\begin{array}{l}\text { (Erreur ! Source du renvoi } \\
\text { (Erreur ! Source du renvoi } \\
\text { introuvable.) }\end{array}$ \\
\hline
\end{tabular}

${ }^{a}$ Species profiles in a premixed laminar flame.

${ }^{\mathrm{b}}$ Flame speed, temperature is then the unburned gases temperature.

${ }^{c}$ Species profiles in a nonpremixed laminar flame.

${ }^{\mathrm{d}} \mathrm{BR}$, batch reactor; FR, flow reactor; RCM, rapid compression machine; ST, shock tube; JSR, jet-stirred reactor.

To our knowledge, only two studies were performed on kinetic measurements related to the oxidation of ethylcyclohexane: in 2009, Vanderover et al. (35) measured the ignition delay times of a mixture of ethylclohexane/air in a shock tube $(T=881-1319 \mathrm{~K} ; \mathrm{P}=10.8-69.5$ bar; $\Phi=0.25-1)$ but did not perform any attempt of modeling. In 2011, Ji et al. (27) measured the laminar flame speeds of ethylcyclohexane/air mixtures in the counterflow configuration at atmospheric pressure $(T=353 \mathrm{~K}$; $\Phi=0.7-1.5$ ). A good simulation of these results was obtained using the JetSurF 1.1 mechanism (44).

The purpose of this paper is to present results on the low- and intermediate-temperature oxidation of ethylcyclohexane in a jet-stirred reactor, with careful identification and analysis of the products.

\section{Experimental Method}

This study of the oxidation of ethylcyclohexane has been performed in a jet-stirred reactor which can be modeled as a perfectly stirred reactor $(45,46)$. This reactor has been used by our research team in Nancy for numerous gas-phase kinetic studies (e.g., refs 47-49). The influence of surface reactions has been shown to be very minor in this kind of reactor (50). Experiments were performed under a constant pressure of 1.06 bar ( 800 Torr), at a residence time of $2 \pm 0.03 \mathrm{~s}$, temperatures ranging from 500 to $1100 \mathrm{~K}$, for the three equivalence ratios of $0.25,1$, and 2 . Helium was used as diluent, and the study was performed with a fuel mole fraction of 0.005. Ethylcyclohexane, helium, and oxygen were provided by Sigma-Aldrich (purity $\geq 99 \%$ ) and Messer (purity of $99.999 \%$ for $\mathrm{He}$ and $99.995 \%$ for $\mathrm{O}_{2}$ ), respectively. Concerning the determination of equivalence ratios and fuel mole fraction, note that the main error is due to the error in the mass flow measurements (using Bronkhorst High-Tech Mass Flow Controller) which leads to an error of about $1 \%$.

The reactor, made of fused silica, consists of a quartz sphere (volume $=95 \mathrm{~cm}^{3}$ ) into which diluted reactants enter through an injection cross located at its center. It is operated under constant temperature and pressure and preceded by an annular preheating zone in which the temperature of the gases is progressively increased up to the reactor temperature. Gas mixture residence time inside the annular preheater is very short compared to its residence time inside the reactor (a few percent). Both the spherical reactor and the annular preheating zone are heated by resistances rolled up around the walls.

The outlet products were analyzed online by gas chromatography. Online analysis of products liquid under standard conditions was allowed by a heated transfer line between the reactor outlet and the chromatograph sampling valves which were also heated. During the study the temperature of the 
transfer line was set at $473 \mathrm{~K}$. This temperature was high enough to keep all the reaction products in the gas phase.

Three gas chromatographs were used for quantification of the different species. The first gas chromatograph, equipped with a Carbosphere packed column, a thermal conductivity detector (TCD), and a flame ionization detector (FID), was used for quantification of $\mathrm{O}_{2}, \mathrm{CO}, \mathrm{CO}_{2}$, methane, ethylene, acetylene, and ethane. Among the products which are known to be important for hydrocarbon oxidation, only hydrogen, water, and formaldehyde were not quantified, but the presence of the two last one is well shown in GC-MS analyses. The second one was fitted with a PlotQ capillary column and a FID and used for quantification of $\mathrm{C}_{1}-\mathrm{C}_{4}$ hydrocarbons and small oxygenated compounds. The third one was fitted with a HP-5 capillary column and a FID and used for quantification of hydrocarbons and oxygenated species with more than five heavy atoms (i.e., carbon and oxygen atoms). Calibration was performed by injecting known amounts of pure substances when available; otherwise, the method of the effective carbon number (51) was used (species having the same number of carbon atoms and the same functional groups were assumed to have the same response in the FID). Calculated uncertainties on the species quantifications were about $\pm 5 \%$ with online analysis of oxygen and $C_{1}-C_{2}$ hydrocarbons and about $\pm 10 \%$ for analysis of other species. The detection threshold is better than $1 \mathrm{ppm}$ for hydrocarbons and $100 \mathrm{ppm}$ for carbon oxides quantified by TCD.

Identification and calibration of light species (e.g., carbon oxides, $C_{1}-C_{4}$ hydrocarbons) were performed by injecting gaseous samples provided by Messer and Air Liquide. Identification of species which were not calibrated before was performed using a fourth gas chromatograph coupled with a mass spectrometer (GC-MS) operating under the same conditions as the gas chromatograph used for quantification, enabling direct comparison of both chromatograms. Identification of these species was not performed "online". The reaction products were condensed in a trap located at the outlet of the reactor and maintained at the temperature of liquid nitrogen. The content of the trap was then analyzed by GC-MS. Mass spectra of all detected reaction products were included in the spectra database "NIST 08", except those with a molecular weight of 126 apart from 7-oxabicyclo[4.3.0]nonane. Note that the software of library identification of the MS always provides an answer, but when the proposed identification looked strongly unlikely according to the possible chemical pathways, a careful deciphering of the mass spectrum was necessary. Their deciphering was performed based on the experience gained in analysis of the oxygenated compounds formed during oxidation of alkanes (52).

\section{Experimental Results}

A table giving the complete set of experimental results for ethylcyclohexane is given as Supporting Information. Table 2 presents the 47 reaction products with a molecular weight lower than that of ethylcyclohexane $(112 \mathrm{~g} / \mathrm{mol})$, which have been quantified online by gas chromatography. Figures 17 display the evolution as a function of temperature of the mole fractions of the reactants (ethylcyclohexane and oxygen) and of these 47 reaction products. 

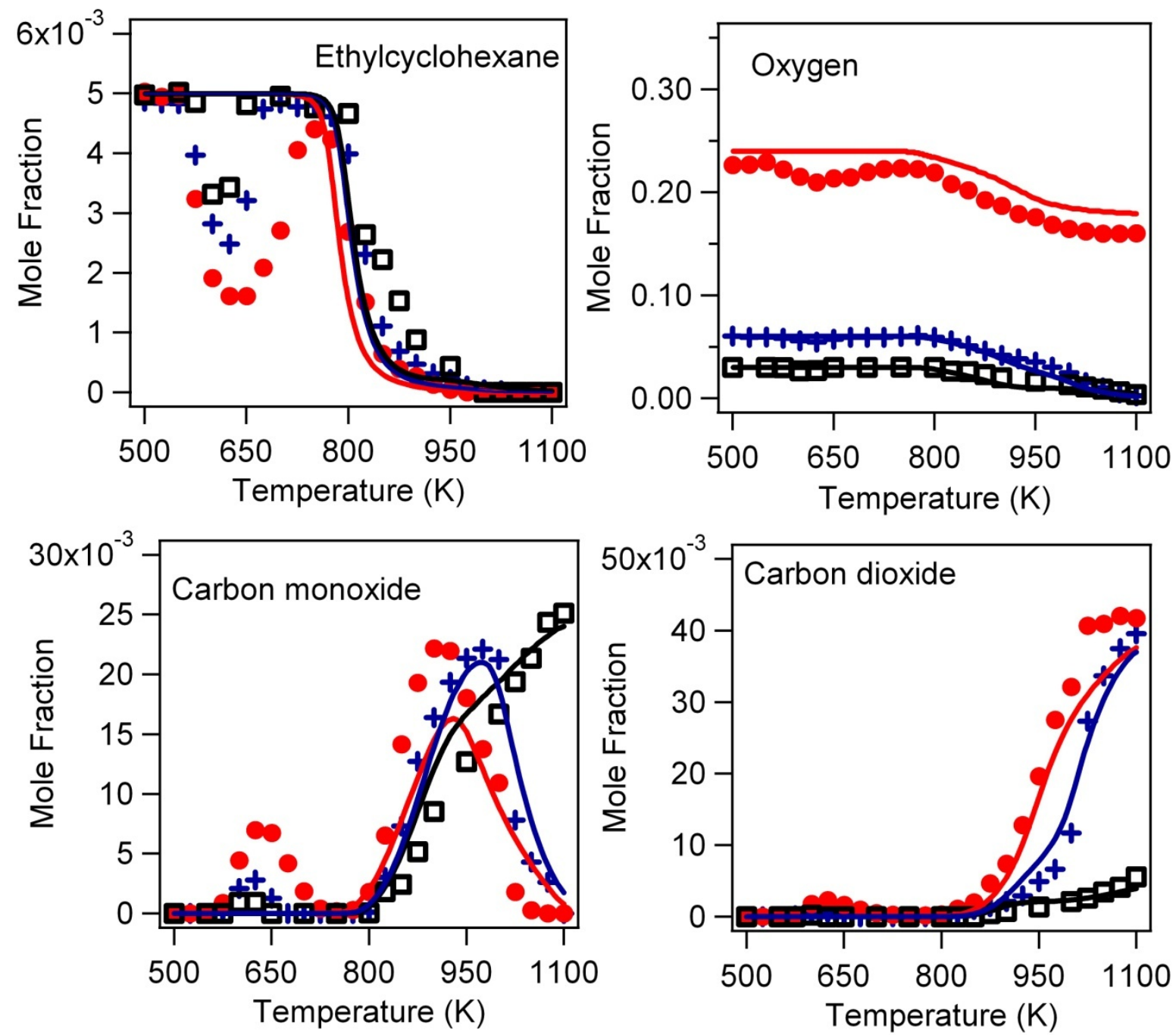

Figure 1. Evolution of the mole fractions of the reactants and carbon oxides with temperature for 3 equivalence ratios: $(\bullet) \phi=0.25 ;(+) \phi=1 ;(\square) \phi=2$. Symbols are experiments and lines simulations. 

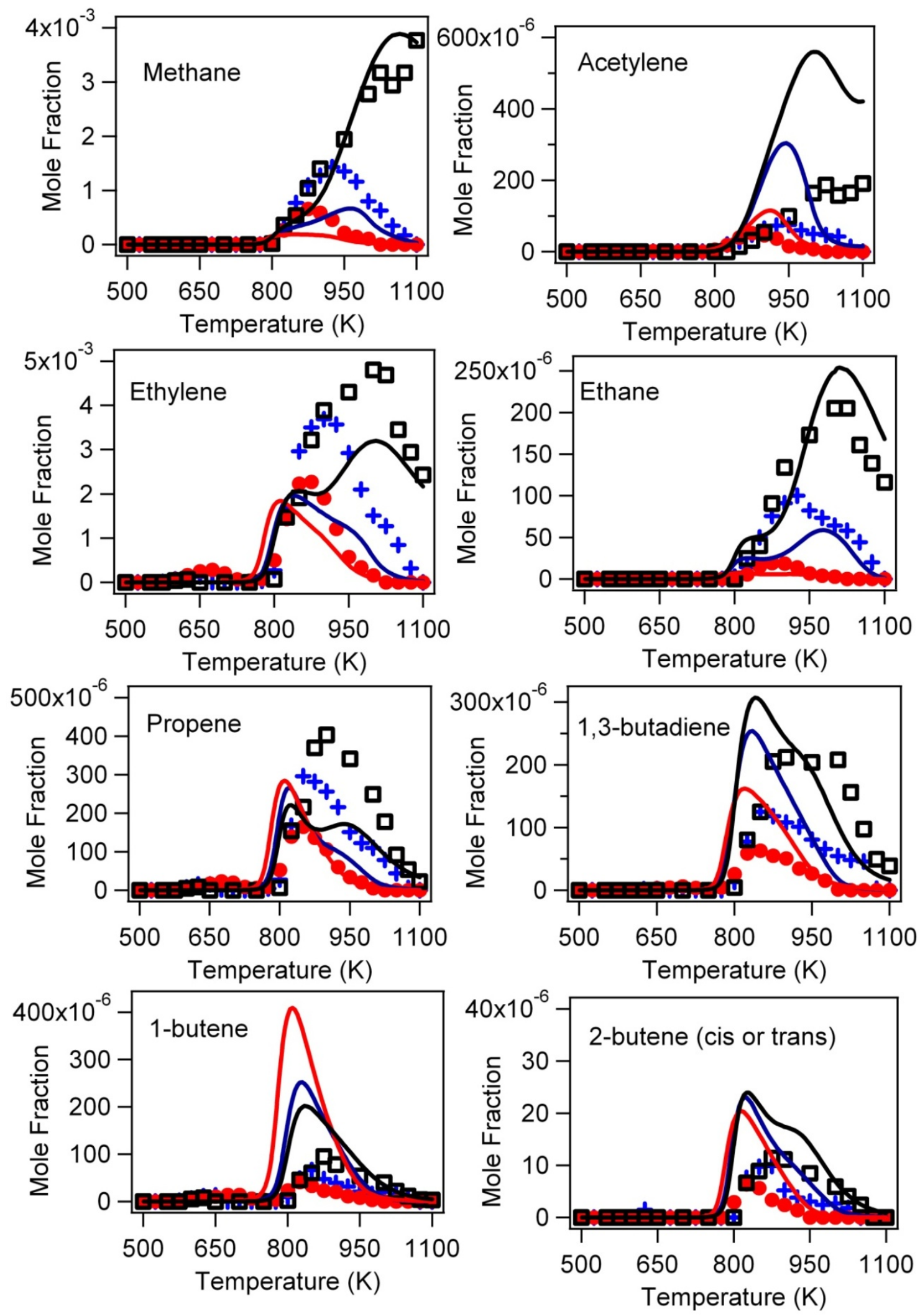

Figure 2. Evolution of the mole fractions of the $C_{1}-C_{4}$ hydrocarbons with temperature for 3 equivalence ratios: $(\bullet) \phi=0.25 ;(+) \phi=1 ;(\square) \phi=2$. Symbols are experiments and lines simulations. 

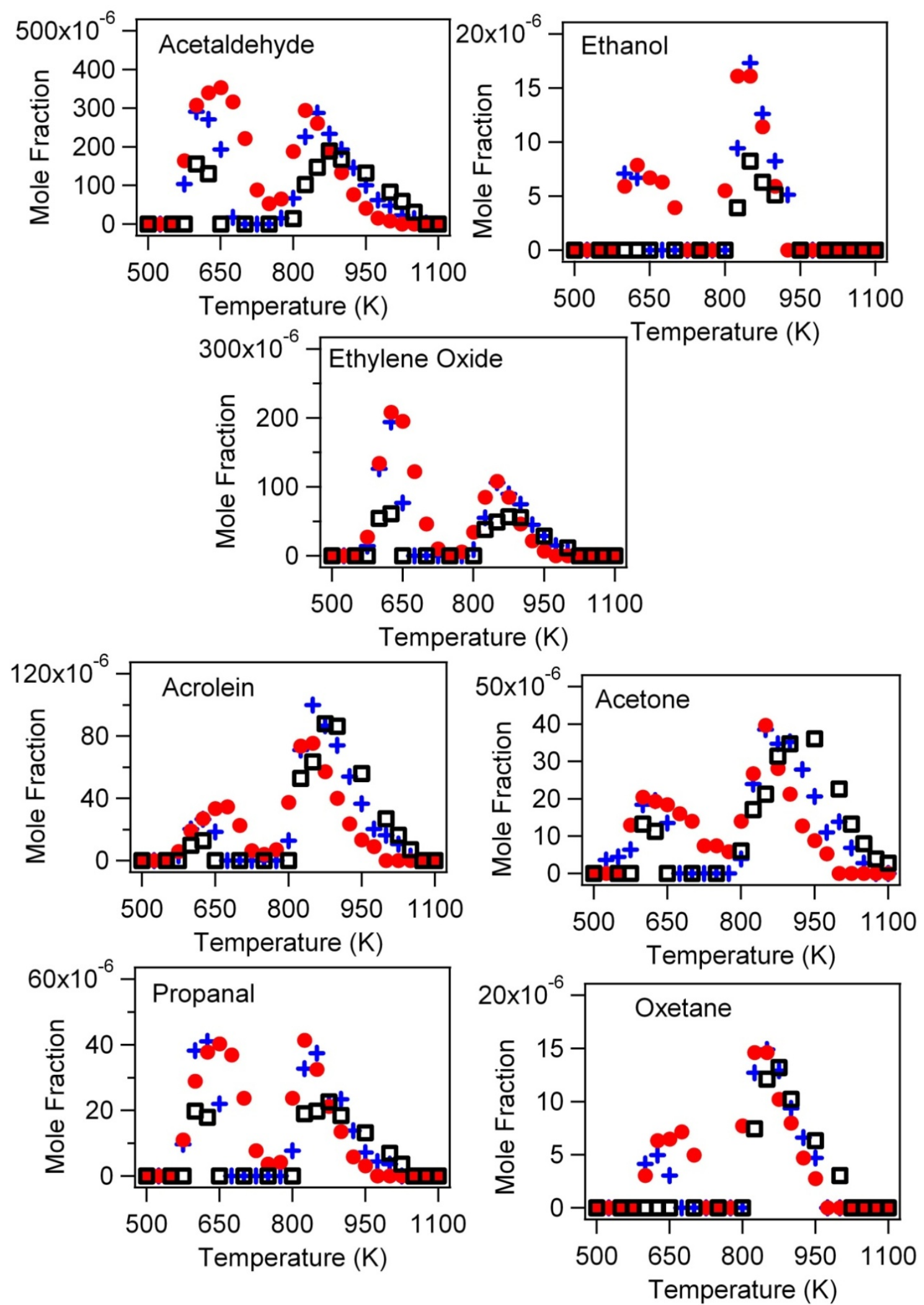

Figure 3. Evolution of the mole fractions of the $C_{2}-C_{3}$ oxygenated species with temperature for 3 equivalence ratios: (•) $\phi=0.25 ;(+) \phi=1 ;(\square) \phi=2$. 

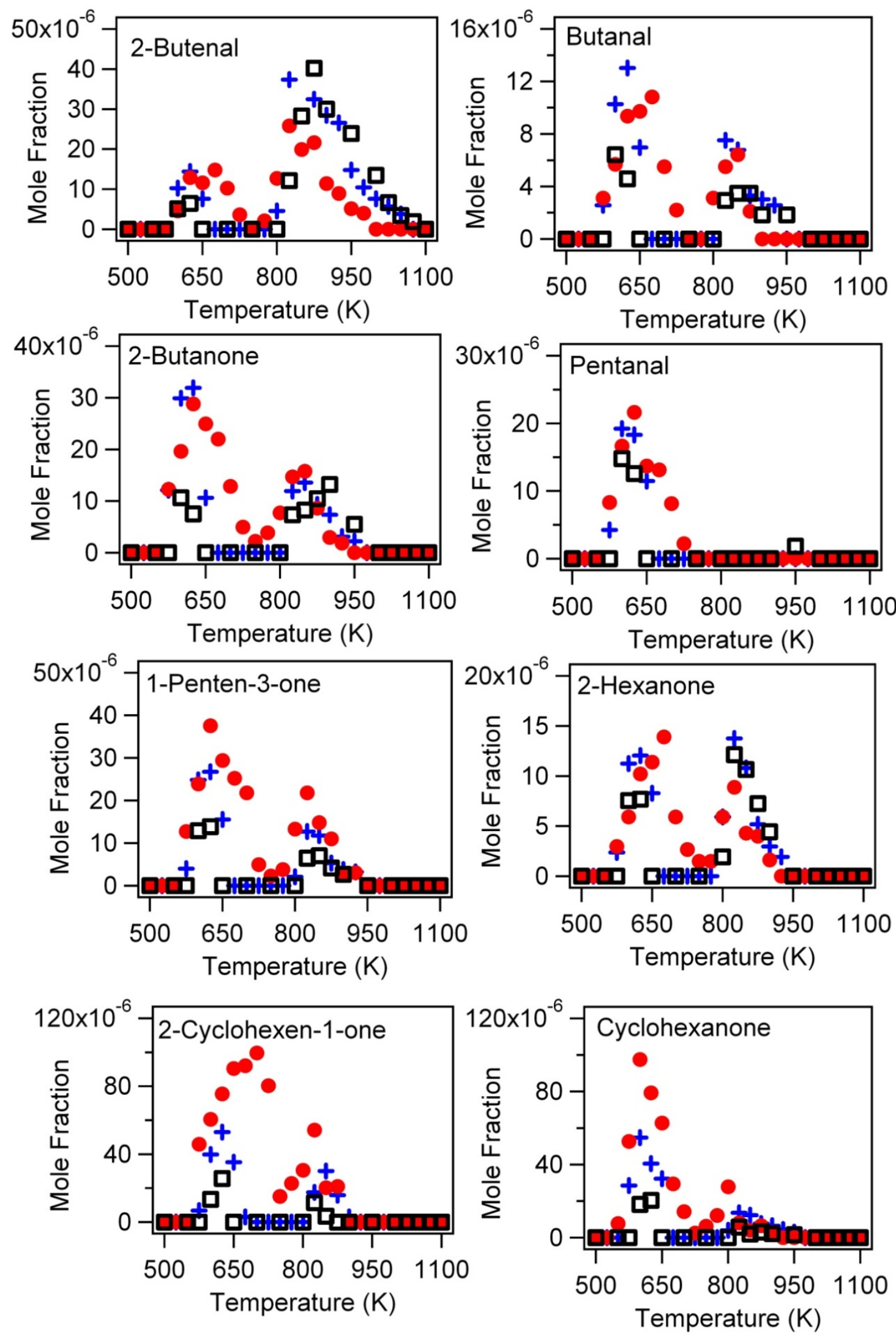

Figure 4. Evolution of the mole fractions of the $C_{4}-C_{6}$ oxygenated species with temperature for 3 equivalence ratios: $(\bullet) \phi=0.25 ;(+) \phi=1 ;(\square) \phi=2$. 

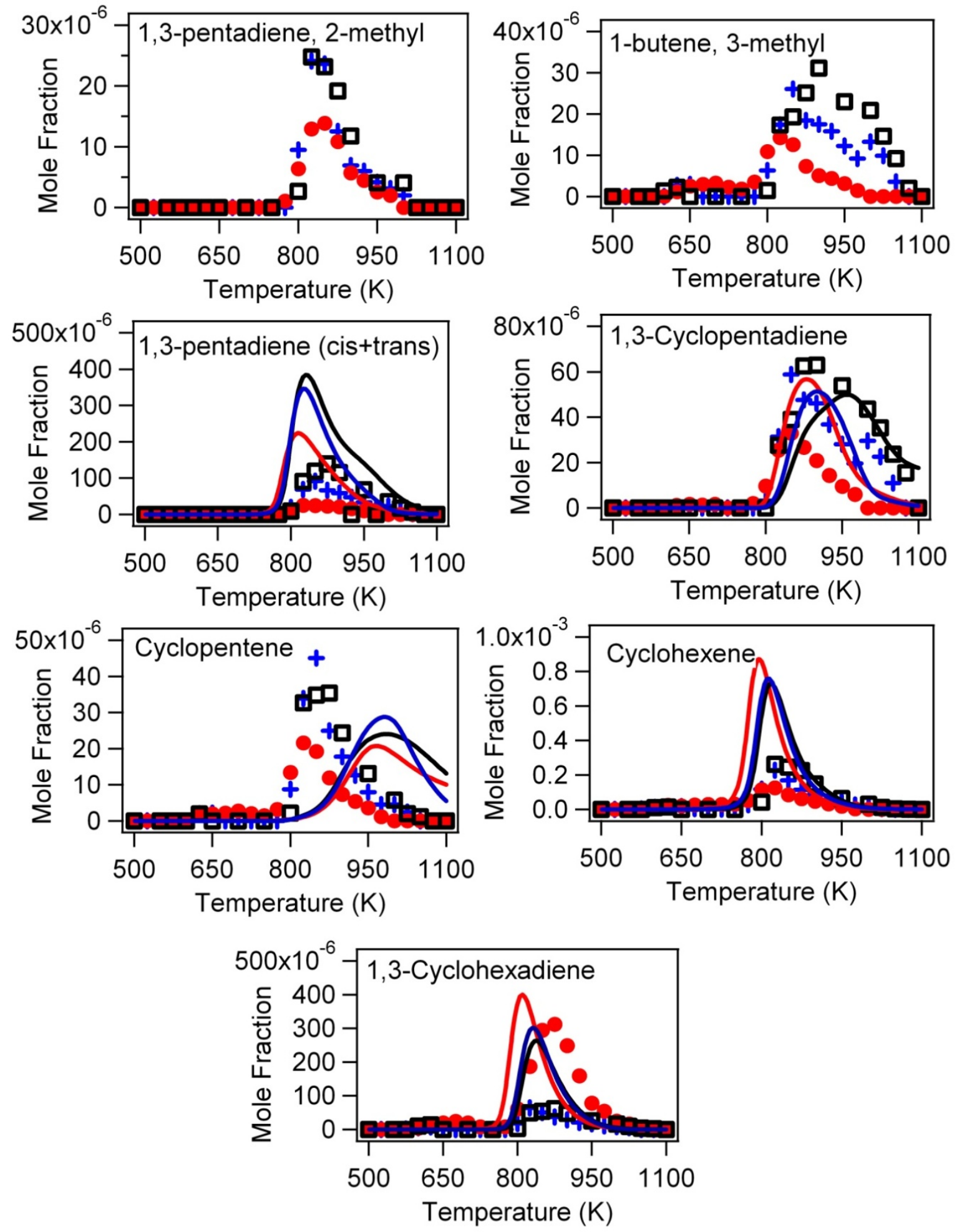

Figure 5. Evolution of the mole fractions of $C_{5}-C_{6}$ nonaromatic hydrocarbons with temperature for 3 equivalence ratios: $(\bullet) \phi=0.25 ;(+) \phi=1 ;(\square) \phi=2$. Symbols are experiments and lines simulations. 

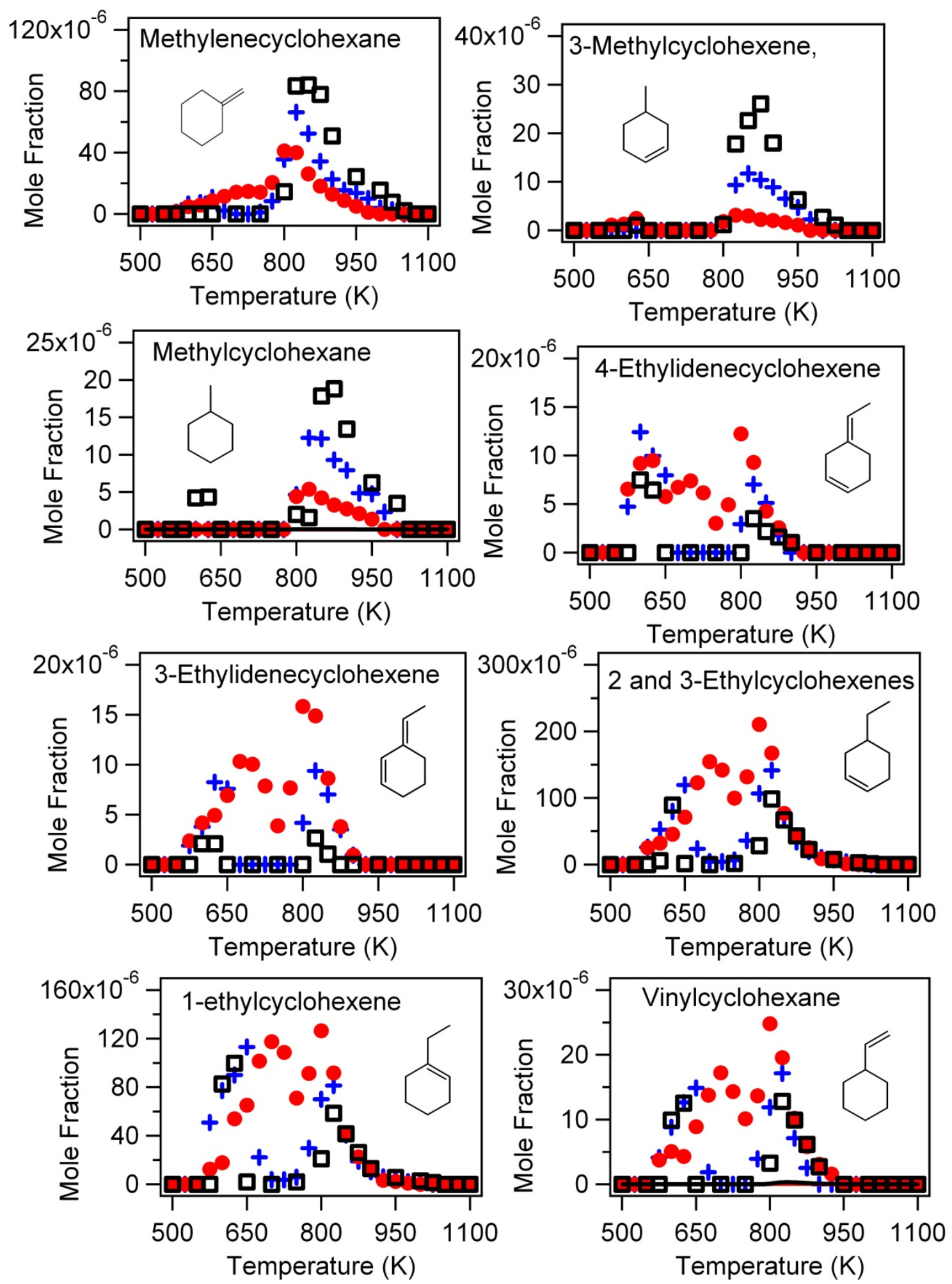

Figure 6. Evolution of the mole fractions of $\mathrm{C}_{7}-\mathrm{C}_{8}$ nonaromatic hydrocarbons with the temperature for 3 equivalence ratios: $(\bullet) \phi=0.25 ;(+) \phi=1 ;(\square) \phi=2$. Symbols are experiments and lines simulations. 

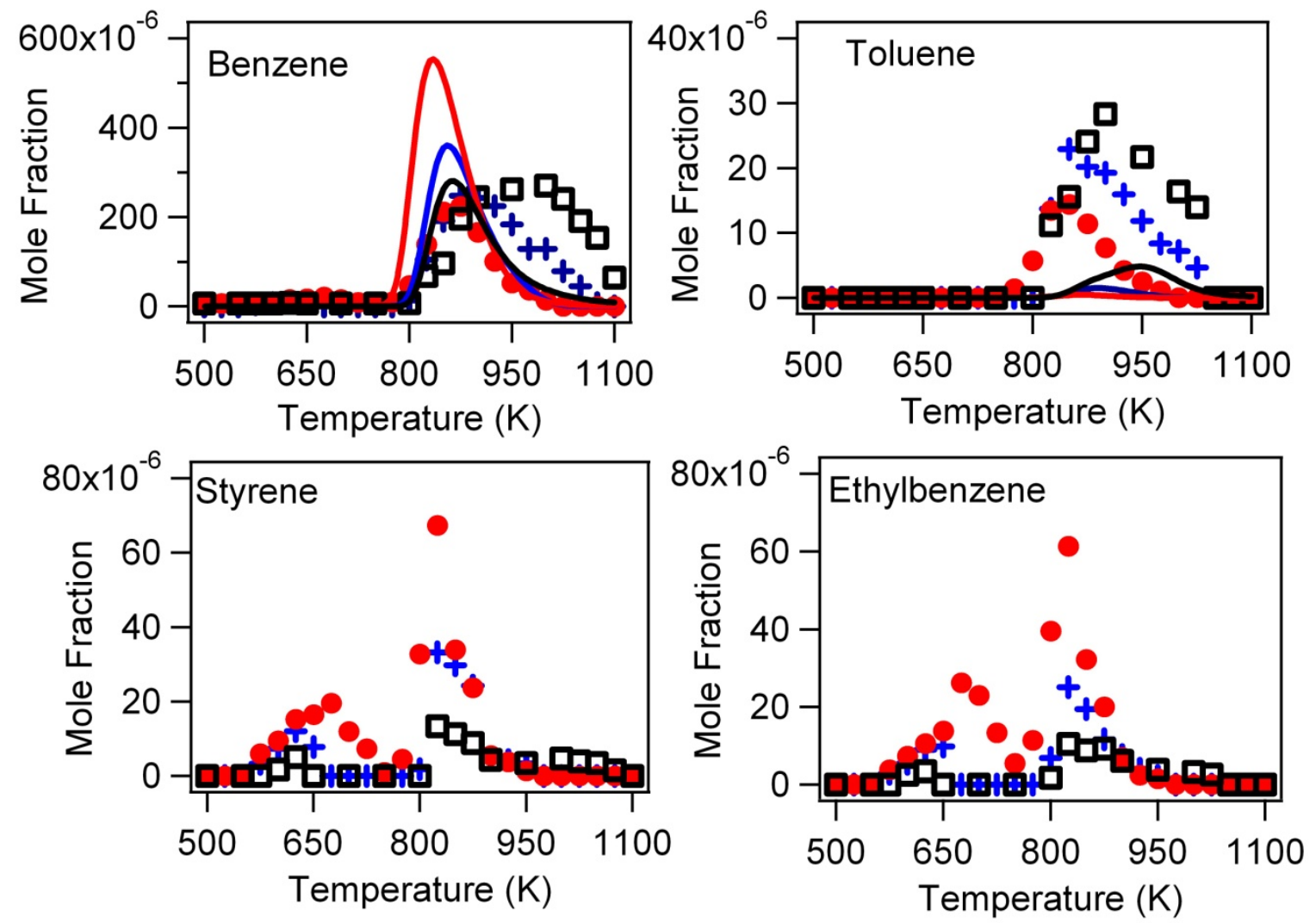

Figure 7. Evolution of the mole fractions of aromatic hydrocarbons with temperature for 3 equivalence ratios: $(\bullet) \phi=0.25 ;(+) \phi=1 ;(\square) \phi=2$. Symbols are experiments and lines simulations.

As shown in Figure 1 the mole fraction profile of ethylcyclohexane and oxygen exhibit a very marked negative temperature coefficient (NTC) behavior. While the equivalence ratio has no real impact on the temperature for which the reactivity starts, it has a significant effect on ethylcyclohexane conversion from 625 to $780 \mathrm{~K}$. The low-temperature reactivity is the largest for an equivalence ratio of 0.25 . The stoichiometric mixture is less reactive, and the rich mixture shows the lowest reactivity. In addition, the extent of the NTC zone and conversion near $625 \mathrm{~K}$ (the temperature of the maximum of reactivity at low temperature) decrease noticeably when the equivalence ratio increases. Above $800 \mathrm{~K}$, the equivalence ratio has a much lower impact. The same conclusion can be derived from the profiles of carbon monoxide. Formation of carbon dioxide occurs mostly above $800 \mathrm{~K}$ and is favored in lean and stoichiometric mixtures. However, as shown by Figure 8, which displays a zoom on the 550-800 K reaction zone for some of the major low-temperature reaction products, formation of 500 ppm of $\mathrm{CO}_{2}$ is encountered at $625 \mathrm{~K}$ in stoichiometric mixtures. 
Table 2. Reaction products (with a mass lower than that of the reactant (112)) identified and quantified during oxidation of ethylcyclohexane $(T=500-1100 \mathrm{~K} ; \phi=0.25,1$, and $2 ; \mathrm{P}=800$ Torr; $\tau=$ $2 \mathrm{~s})$

\begin{tabular}{|c|c|}
\hline $\begin{array}{l}\text { Satured and } \\
\text { unsatured linear } \\
\text { hydrocarbons }\end{array}$ & $\begin{array}{l}\text { methane, ethane, ethylene, acetylene, propene, 1-butene, 1,3-butadiene, 2-butene (cis } \\
\text { and trans), 1-butyne (traces), 1,3-pentadiene (cis \& trans) }\end{array}$ \\
\hline $\begin{array}{c}\text { Branched } \\
\text { hydrocarbons }\end{array}$ & 3-methyl-1-butene, 2-methyl-1,3-pentadiene [ethylbutadiene] ${ }^{a, b}$ \\
\hline Aldehydes & acetaldehyde, acrolein (2-propenal), propanal, butanal, 2-butenal, pentanal \\
\hline Ketones & acetone, 2-butanone, 2-hexanone, 1-penten-3-one \\
\hline $\begin{array}{l}\text { Cyclic oxygenated } \\
\text { species }\end{array}$ & ethylene oxide, oxetane, cyclohexanone, 2-cyclohexen-1-one \\
\hline $\begin{array}{l}\text { Other oxygenated } \\
\text { species }\end{array}$ & carbon oxides, ethanol, acetic acid \\
\hline Aromatics & benzene, toluene, ethylbenzene, styrene \\
\hline $\begin{array}{l}\text { Cyclic } \\
\text { hydrocarbons }\end{array}$ & 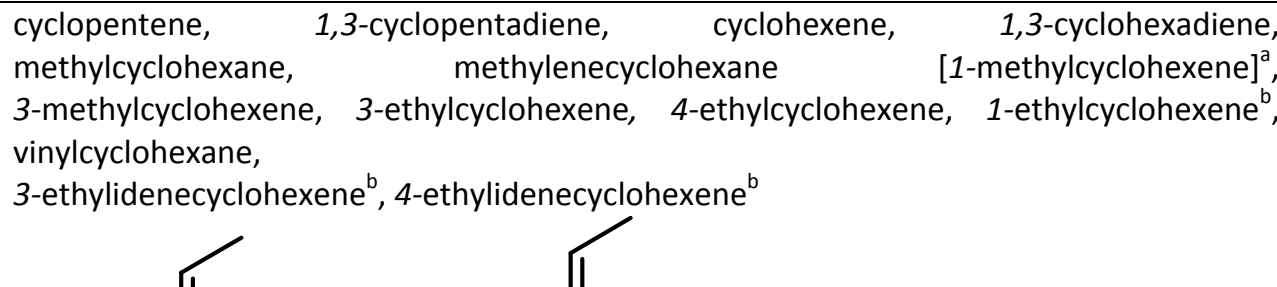 \\
\hline
\end{tabular}

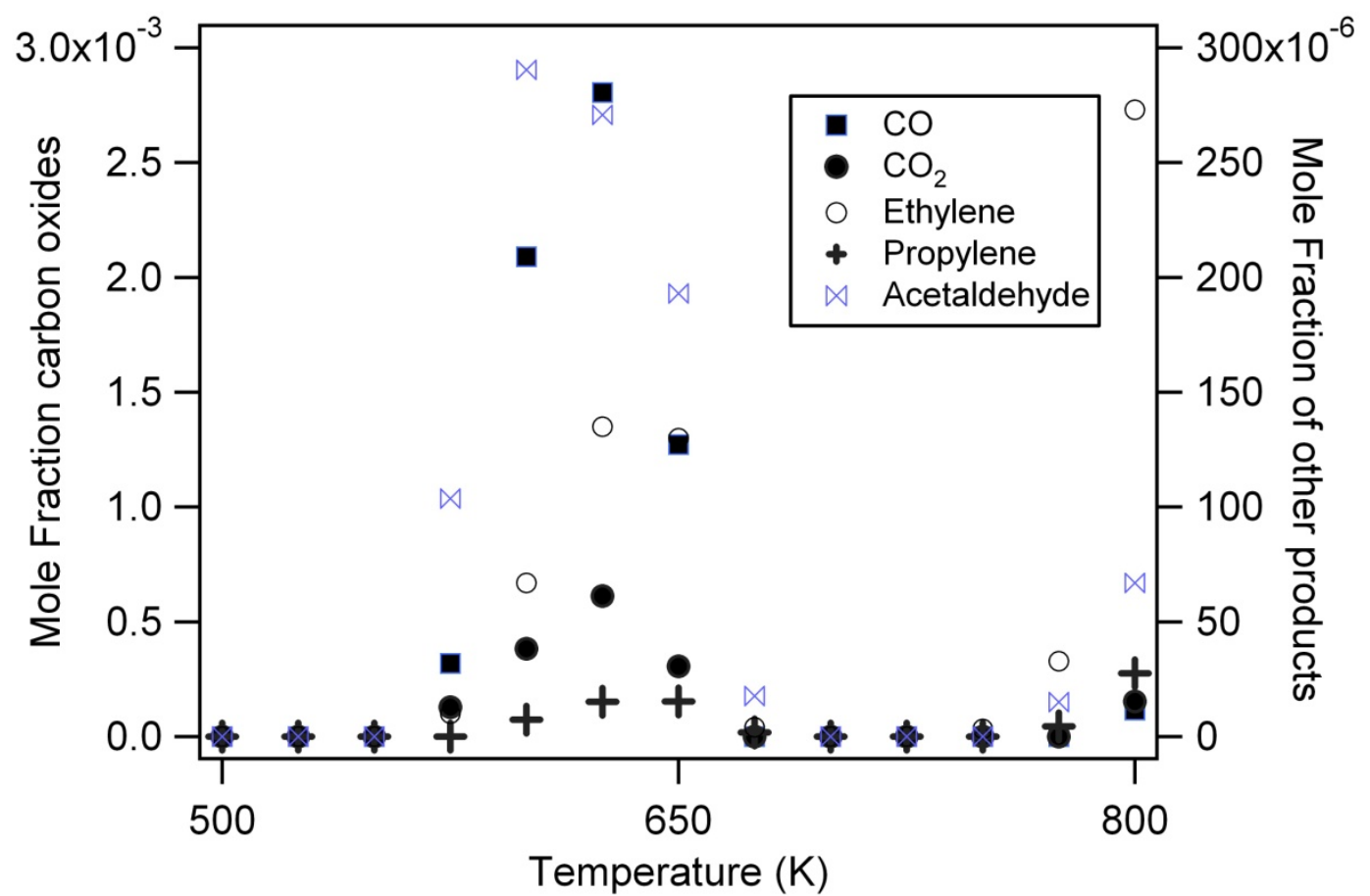

Figure 8. Zoom on the $550-800 \mathrm{~K}$ reaction zone for some of the major low-temperature reaction products for a stoichiometric mixture. 
Figure 2 presents the evolution with temperature of the mole fractions of the $C_{1}-C_{4}$ hydrocarbons. Below $800 \mathrm{~K}$, the only species of this type which have been detected are ethylene, propene, and 1-butene. As shown in Figure 8, at $625 \mathrm{~K}$ in stoichiometric mixtures, 140 and $20 \mathrm{ppm}$ of ethylene and propene are formed, respectively. Above $800 \mathrm{~K}$, large concentrations of these species are formed especially in the rich mixture, the major ones being methane, ethylene, and propene. Noticeable amounts (up to $200 \mathrm{ppm}$ in rich mixtures) of acetylene and 1,3-butadiene are also observed.

Figure 3 displays the evolution with temperature of the mole fractions of $C_{2}-C_{3}$ oxygenated species. Large concentrations of these species are formed even below $800 \mathrm{~K}$, demonstrating again the high reactivity of ethylcyclohexane at low temperature. The most abundant species of this type is acetaldehyde with a maximum around $600 \mathrm{~K}$ of about 300 and $400 \mathrm{ppm}$ under stoichiometric and lean conditions, respectively. Note that as shown in Figure 8 the maximum of acetaldehyde occurs at lower temperature than that of carbon oxides and small alkenes. Note also that an important formation of acetic acid was also observed in a similar amount as acetaldehyde in lean mixtures and below $800 \mathrm{~K}$ but with a higher sensitivity to the change in equivalence ratios than that of the aldehyde. We have no evidence showing this behavior for other intermediates, except perhaps compounds including two carbonyl groups. This profile of acetic acid is not presented in Figure 3, because as shown by Herbinet et al. (49) in the case of $n$-heptane its formation is probably mostly due decomposition of ketohydroperoxides in the transfer line. Among other important products are ethylene oxide, acrolein (up to $300 \mathrm{ppm}$ in lean mixtures), and propanal. Formation of these species is favored in lean mixtures.

Figure 4 presents the evolution with temperature of the mole fractions of $\mathrm{C}_{4}-\mathrm{C}_{6}$ oxygenated species, which are also more easily formed in lean mixtures. Formation of these species is lower than that of most of the smaller oxygenated species and favored below $800 \mathrm{~K}$, apart from 2-butenal. The most abundant of these species are the cyclic ones: cyclohexanone and cyclohexenone (with mole fraction up to $120 \mathrm{ppm}$ at $625 \mathrm{~K}$ under lean conditions).

Figure 5 presents the evolution with temperature of the mole fractions of $C_{5}-C_{6}$ nonaromatic hydrocarbons which are all mainly produced above $800 \mathrm{~K}$. Cyclic $\mathrm{C}_{6}$ species (1,3-cyclohexadiene and cyclohexene) are the most abundant hydrocarbons formed during this study apart from $\mathrm{C}_{1}-\mathrm{C}_{3}$ species, with a maximum of $300 \mathrm{ppm}$. Note that 1,3-cyclohexadiene is formed in larger amounts in lean mixtures, while formation of all other produced $C_{1}-C_{6}$ hydrocarbons is larger in rich mixtures. Cyclic $\mathrm{C}_{5}$ species (1,3-cyclopentadiene and cyclopentene) are much less abundant with a maximum of 70 and 50 ppm, respectively. The most abundant of the acyclic species is 1,3-pentadiene (with a maximum mole fraction of $130 \mathrm{ppm}$ ). Two chromatographic peaks have been observed corresponding to the cis and trans isomers, but it has not been possible to attribute a peak to a given isomer.

Figure 6 presents the evolution with temperature of the mole fractions of $C_{7}-C_{8}$ nonaromatic hydrocarbons. Methylenecyclohexane is the most abundant among $C_{7}$ products, with a maximum of $90 \mathrm{ppm}$ at $875 \mathrm{~K}$ under rich conditions but also slight formation at lower temperature (up to $10 \mathrm{ppm}$ at $625 \mathrm{~K}$ in lean mixtures). All $\mathrm{C}_{8}$ products have similar mole fractions below and above $800 \mathrm{~K}$ with a marked NTC behavior in rich and stoichiometric mixtures. Under lean conditions formation of these products is significantly favored and the NTC behavior is much less pronounced. The most abundant of these species are ethylcyclohexene isomers with a maximum total formation of $270 \mathrm{ppm}$. It was not possible to distinguish between the 2- and the 3-ethylcyclohexenes. Formation of vinylcyclohexane is much lower (up to $25 \mathrm{ppm}$ ). Note that among unsaturated $\mathrm{C}_{8}$ compounds vinylcyclohexane and ethylidenecyclohexenes have been observed but not ethylidenecyclohexane or vinylcyclohexenes. In addition, while their formation could have been expected, no ethylcyclohexadiene was detected in noticeable amounts. While isomers of heptene have been detected in flames of methylcyclohexane by Skeen et al. (36), acyclic $\mathrm{C}_{8}$ compounds of the same mass 
as the reactant were not observed in the present study, even in rich mixtures. Formation of isomers of octane could be obtained through an internal disproportionation of biradicals formed from the cyclic reactant by unimolecular initiations involving breaking of a $\mathrm{C}-\mathrm{C}$ bond in the ring.

Figure 7 presents the evolution with temperature of the mole fractions of the four aromatic hydrocarbons analyzed. Benzene is the aromatic species formed in the largest amount (up to 260 $\mathrm{ppm}$ at $875 \mathrm{~K}$ ). However, like toluene, it is only formed above $800 \mathrm{~K}$. Ethylbenzene and styrene are formed in lower amounts (up to $70 \mathrm{ppm}$ ) but are produced also in a noticeable way below $800 \mathrm{~K}$.

In addition to these products of molecular weight lower than that of ethylcyclohexane (molecular weight $=112)$, a lot of molecules having a molecular weight of $126\left(\mathrm{C}_{8} \mathrm{H}_{14} \mathrm{O}\right.$ formula) were detected in a large amount. Figure 9 displays the evolution with temperature of the total mole fraction of these species, which are formed both below and above $800 \mathrm{~K}$ and are more abundant in lean mixtures, especially above $625 \mathrm{~K}$ (up to $1000 \mathrm{ppm}$ for the sum of these isomers). The equivalence ratio has a larger impact on formation of these species from 650 to $850 \mathrm{~K}$ than at lower temperatures, which lead us to think that the low-temperature mechanism is certainly still important above $800 \mathrm{~K}$ in lean mixtures.

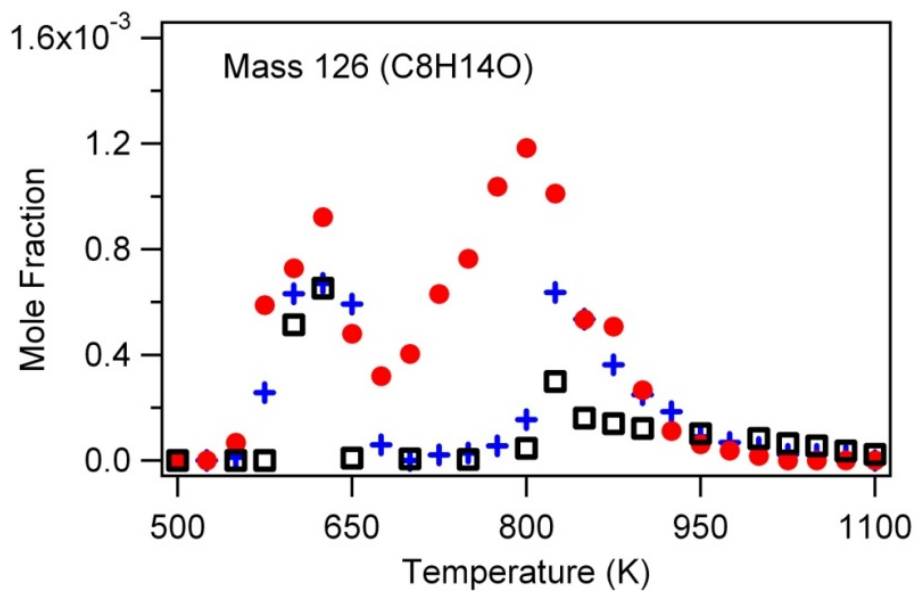

Figure 9. Evolution of the total mole fraction of the species with a molecular weight of 126 with temperature for 3 equivalence ratios: $(\bullet) \phi=0.25 ;(+) \phi=1 ;(\square) \phi=2$.

Among these $\mathrm{C}_{8} \mathrm{H}_{14} \mathrm{O}$ products, interpretation of mass spectra has allowed us to propose a structure for the 8 compounds which are listed in Table 3. An example of a chromatogram related to these products is given in Figure 10. Mass spectra of the 7 compounds with a molecular weight of 126 which were identified in addition to 7-oxabicyclo[4.3.0]nonane are given as Supporting Information. As shown in Figure 10, the chromatograms also include many small peaks for which a reliable identification was not possible. For longer residence times other small peaks could correspond to compounds with a $\mathrm{C}_{8} \mathrm{H}_{12} \mathrm{O}_{2}$ formula (a molecular weight of 140). These compounds could be species including two carbonyl groups in the same way as what has recently been observed during oxidation of n-butane (48) and n-heptane (49). Figure 11 presents the evolution with temperature of the mole fractions of the seven $\mathrm{C}_{8} \mathrm{H}_{14} \mathrm{O}$ species for which quantification was possible. It shows that octenone is the most abundant of that type of compound with a larger formation under lean conditions and a higher maximum at $825 \mathrm{~K}$ (up $700 \mathrm{ppm}$ ) than at $625 \mathrm{~K}$ (up $400 \mathrm{ppm}$ ). Formation of this unsaturated ketone is notably more favored in lean mixtures than that of all the other products displayed in Figure 11. The bicyclic ethers, with both cycles sharing at least a bond, are formed in similar amounts whatever the size of the additional ring: 3 or 5 members (maximum at $625 \mathrm{~K}$ of about $90 \mathrm{ppm}$ ). 3-Methyl,2-oxaspiro[1,5]octane and cyclohexylmethylketone are formed in lower amounts (maximum at $625 \mathrm{~K}$ below $50 \mathrm{ppm}$ ). 


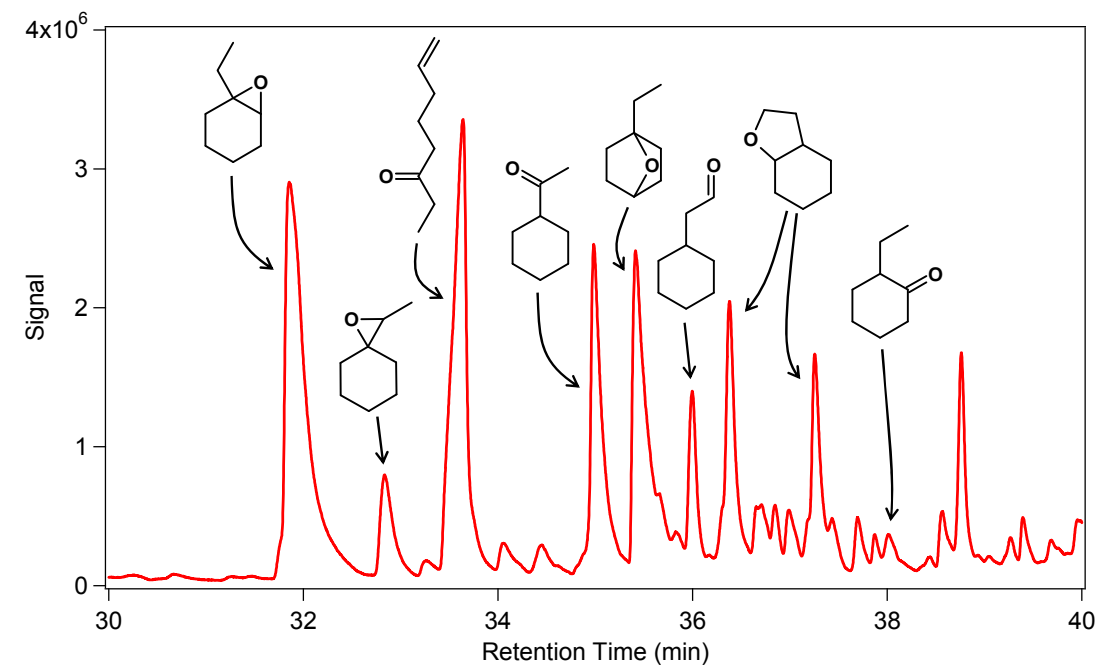

Figure 10. Example of chromatogram obtained with mass spectrometry detection for products with a molecular weight of 126 .
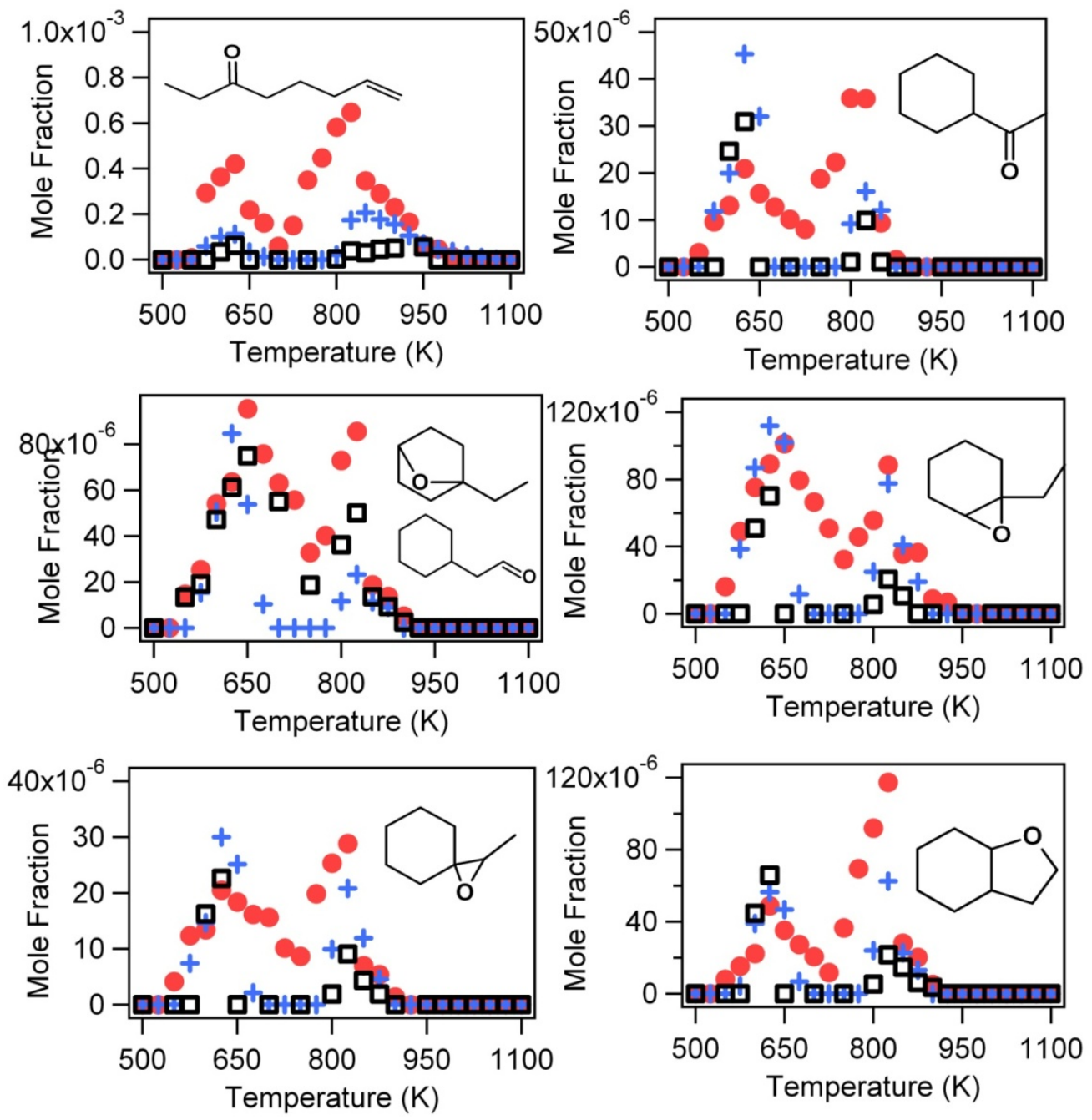

Figure 11. Evolution with the temperature of the mole fractions of the species with a molecular weight of 126 which can be quantified: $(\bullet) \phi=0.25 ;(+) \phi=1 ;(\square) \phi=2$. 
Table 3. Reaction products (with a mass with a molar mass of 126) identified and quantified during oxidation of ethylcyclohexane

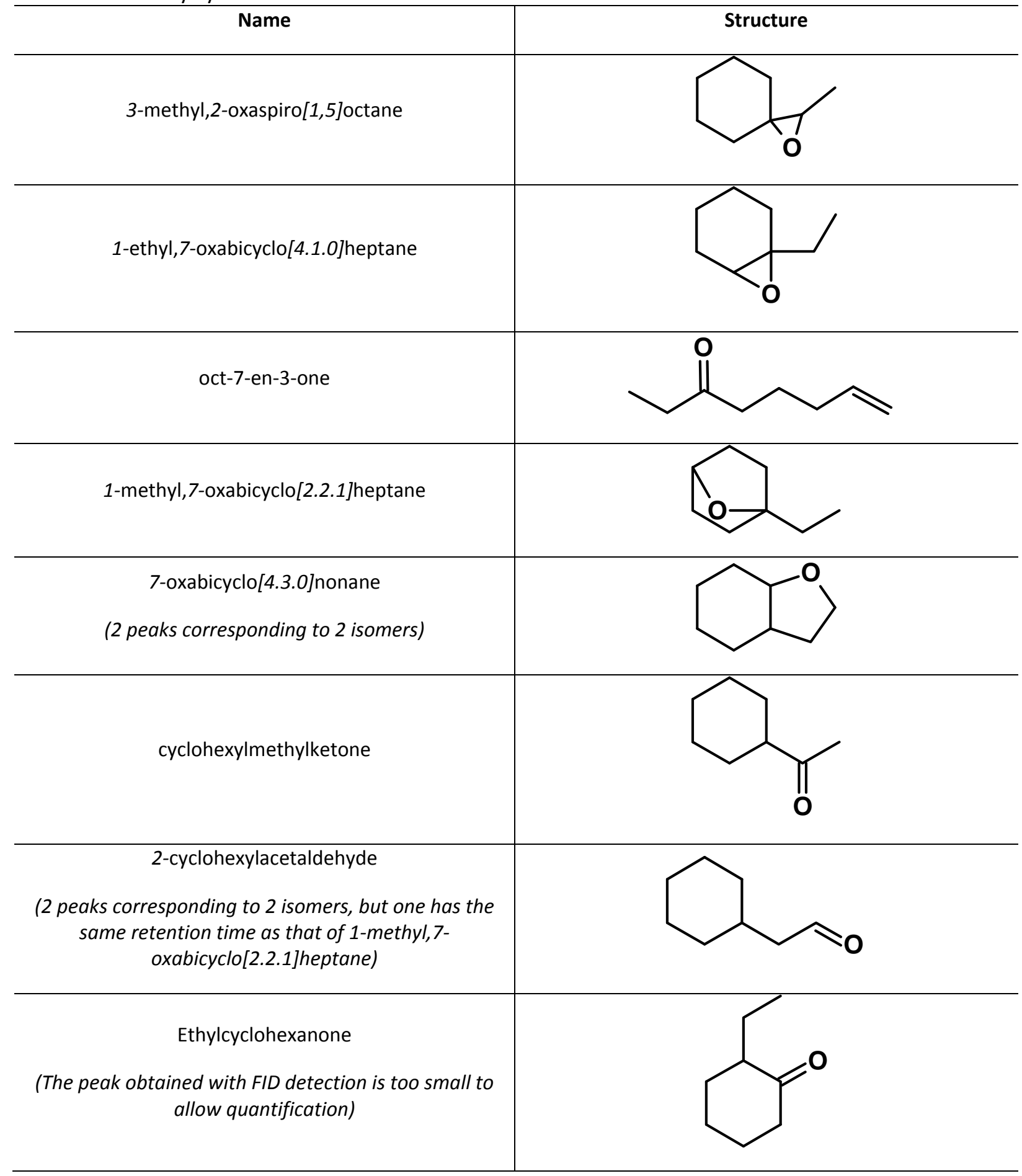

The carbon balance is generally better than $10 \%$, apart from the case of the study of the leanest mixtures $(\phi=0.25)$ around $650 \mathrm{~K}$ for which heavy oxygenated compounds condensing directly at the reactor outlet are certainly formed. 


\section{Discussion}

\section{Comparison with Other $C_{8}$ Hydrocarbon Reactants}

To compare the reactivity of alkcyclohexanes with that of other types of hydrocarbons we studied the oxidation of two other $\mathrm{C}_{8}$ hydrocarbons, $n$-octane and 1-octene, under the same conditions for stoichiometric mixtures. The results are plotted in Figure 12 for the fuel mole fraction and for that of some representative reaction products ( $\mathrm{CO}$, acetaldehyde, $\mathrm{C}_{2} \mathrm{H}_{4}, \mathrm{C}_{2} \mathrm{H}_{2}$, benzene, and ethylene oxide). This figure shows that the reactivity of ethylcyclohexane is very close to that of 1-octene and much lower than that of $n$-octane below $800 \mathrm{~K}$. This is also shown by the much larger formation of carbon monoxide, aldehydes (see acetaldehyde in Figure 12), or alkenes (see ethylene in Figure 12).
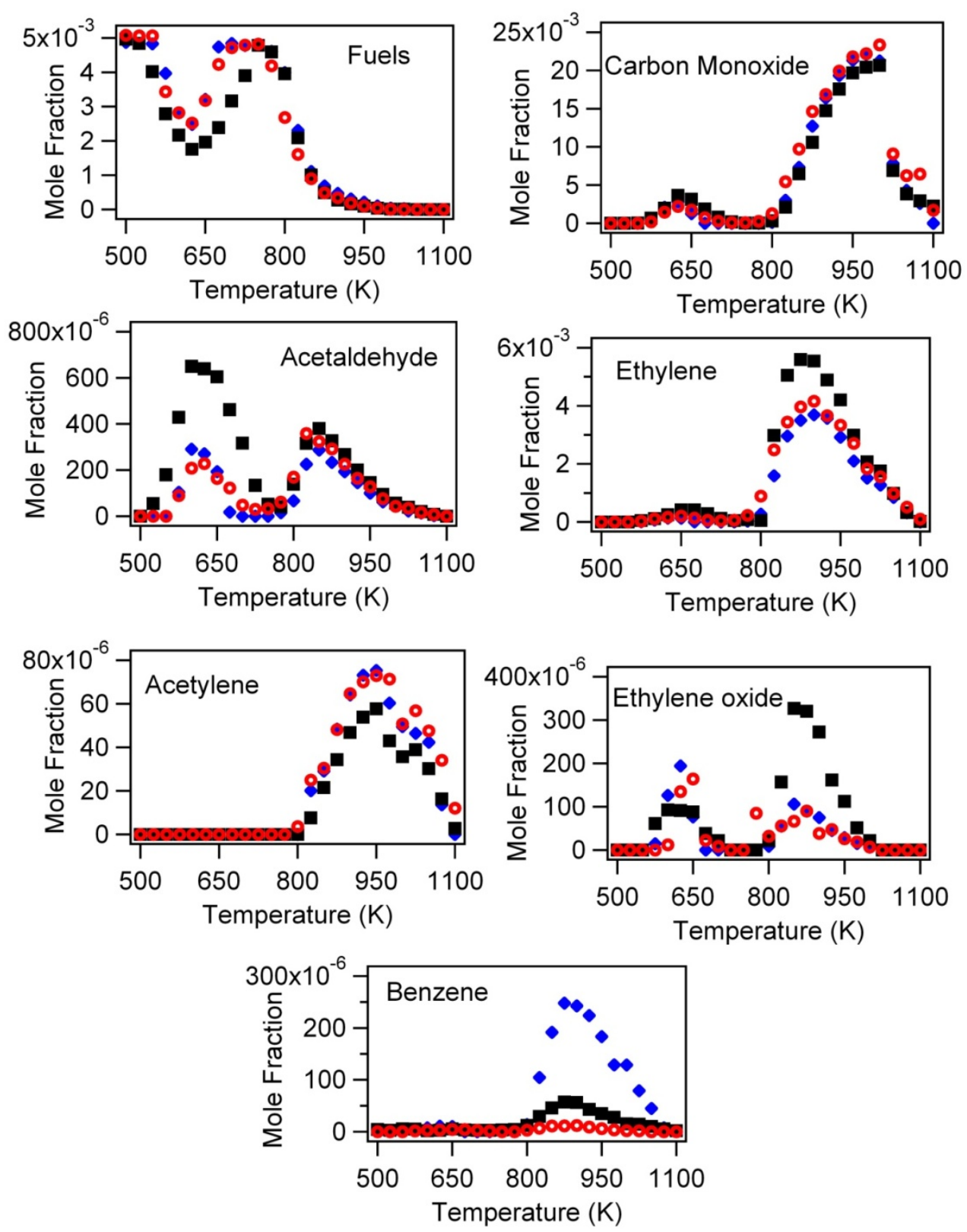

Figure 12. Comparison of the evolution of the mole fractions of the reactants and several products obtained during oxidation of stoichiometric mixtures containing different $\mathrm{C}_{8}$ reactants: $(\diamond)$ ethylcyclohexane; (o) 1-octene; (घ) n-octane. 
In addition, the extent of the NTC zone is much larger for the linear alkane than for the two unsaturated compounds. The presence of the cycle, like that of a double bond, makes isomerization of peroxy radicals more difficult and then hinders the low-temperature reaction. Note however that formation of ethylene oxide is larger for 1-octene and ethylcyclohexane. Above $800 \mathrm{~K}$, the reactivity of the three $\mathrm{C}_{8}$ hydrocarbons is very similar (still slightly larger for $n$-octane) as can be shown by fuel conversion and formation of carbon monoxide and acetaldehyde. However, formation of ethylene and ethylene oxide is larger for the linear alkane than for the alkene and cyclic compounds. On the other hand, formation of acetylene is largest for ethylcyclohexane and 1-octene. It is worth noting that because of the presence of a $\mathrm{C}_{6}$ ring in the molecule formation of benzene is considerably larger in the case of ethylcyclohexane than for the two acyclic $C_{8}$ hydrocarbons. Alkylcyclohexanes are then a favored source of aromatic compounds at intermediate temperatures, which are soot precursors.

\section{Comparison with Simulations Performed with a Mechanism Available in the Literature}

Simulations have been performed using the JetSurF 1.1 mechanism (44), which was already used with success to model laminar flame speeds of ethylcyclohexane/air mixture at atmospheric pressure (27). Since this mechanism has a short globalized low-temperature submechanism we tested it over the full temperature range studied. Comparison between experimental and predicted results is presented in Figures 1, 2, 5, 6, and 7. Figure 1 indicates that the model predicts well the reactivity above $770 \mathrm{~K}$, as shown by the reactants and carbon oxide profiles. At lower temperatures, no reactivity is predicted while a significant experimental one was observed. Prediction of the formation of $\mathrm{C}_{1}-\mathrm{C}_{4}$ hydrocarbons is also relatively good, apart from that of acetylene and 1-butene which is significantly overestimated especially in rich mixture. As formation of oxygenated species by a lowtemperature mechanism is not adequately taken into account, no comparison is presented for the species of Figures 3 and 4 . Figure 5 shows a satisfactory prediction of formation of 1,3-cyclopentadiene, but the agreement is less good for other $C_{5}-C_{6}$ hydrocarbons. Figure 6 shows that while methylcyclohexane and vinylcyclohexane are included in the model, no formation of $C_{7}-C_{8}$ nonaromatic hydrocarbons is predicted. As displayed in Figure 7, formation of benzene is well predicted in rich and stoichiometric mixtures but overestimated in lean mixture. Formation of toluene is considerably underestimated, while that of ethylbenzene and styrene is not considered by the model. Note that the model also predicts noticeable amounts of $\mathrm{H}_{2}, \mathrm{H}_{2} \mathrm{O}, \mathrm{H}_{2} \mathrm{O}_{2}, \mathrm{CH}_{2} \mathrm{O}$, and $\mathrm{CH}_{2} \mathrm{CO}$, which cannot be quantified by the experimental method used in the present study.

\section{Ways of Reactions Important To Explain Formation of the Main Products}

We tried below to identify the reactions which are of importance to explain formation of the main products observed in this study.

\section{- Ways of Reactions Important Above $800 \mathrm{~K}$}

Figure 13 shows a reaction rate analysis for a temperature of $850 \mathrm{~K}$ under the conditions of Figures 1-7 (for stoichiometric mixtures) corresponding to $90 \%$ conversion of ethylcyclohexane. Under these conditions ethylcyclohexane is mainly consumed by $\mathrm{H}$ abstractions mostly with $\mathrm{OH}$ radicals to give the six possible ethylcyclohexyl radicals (RC1-RC6). RC3 radicals can be obtained by abstraction of one tertiary $\mathrm{H}$ atom (13\% of ethylcyclohexane consumption, $\mathrm{RC} 1$ radicals by that of three primary $\mathrm{H}$ atoms; $13 \%$ consumption), RC2 ( $8 \%$ consumption) and RC6 (11\% consumption) radicals by that of 2 secondary H atoms, and finally RC4 ( $28 \%$ consumption) and RC5 ( $24 \%$ consumption) radicals can be produced by abstraction of 4 secondary $\mathrm{H}$ atoms. 


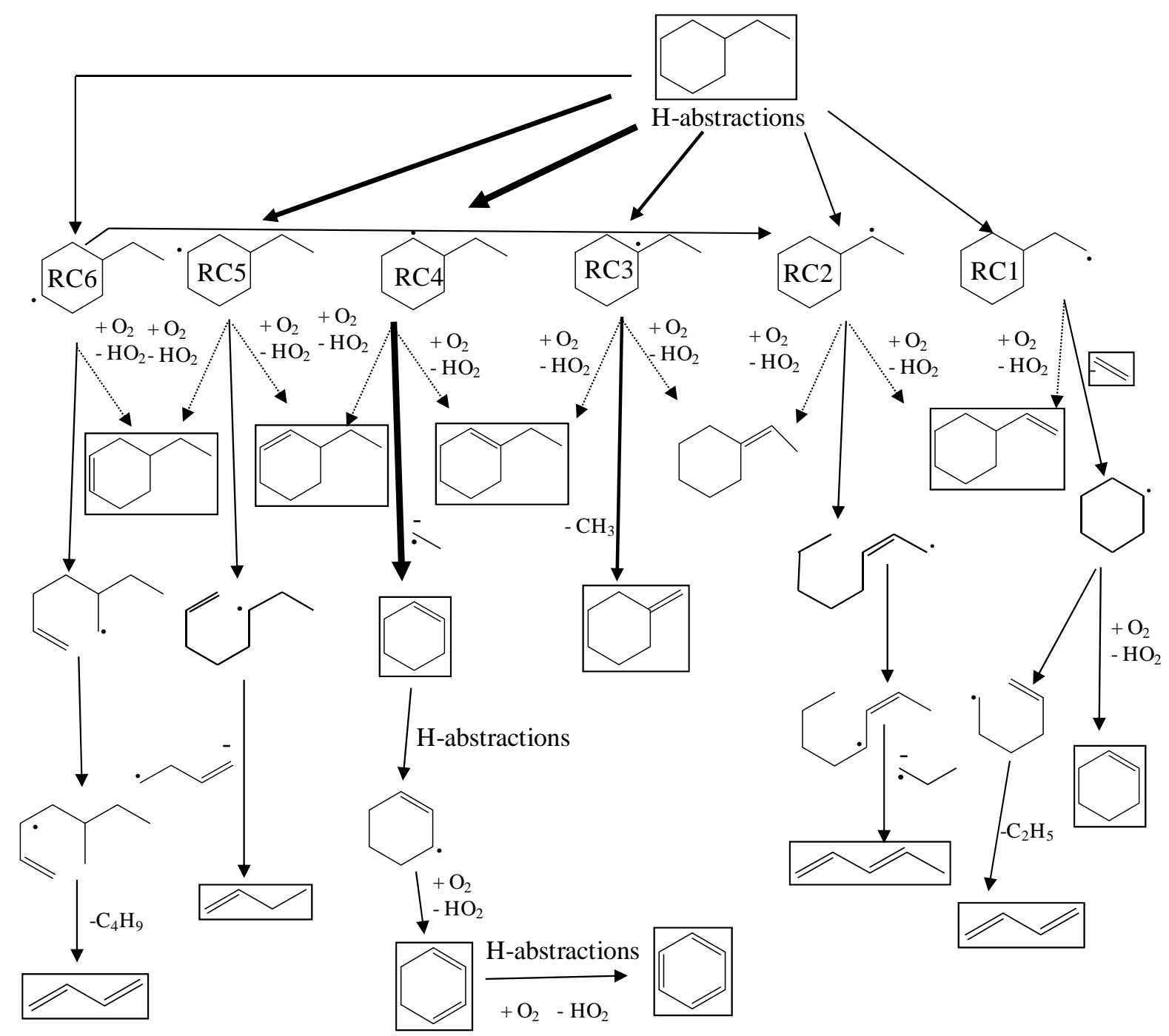

Figure 13. Flow rate analysis for a temperature of $850 \mathrm{~K}$ under the conditions of Figures 1-7 (for a stoichiometric mixture). Size of the arrows is proportional to the flow rate. Dotted arrows show the ways of formation which can be envisaged to explain formation of some main products observed in this study but not predicted by the JetSurF 1.1 mechanism (44).

Above $800 \mathrm{~K}$, the most important type of reaction consuming ethylcyclohexyl radicals is by breaking of a $\mathrm{C}-\mathrm{C}$ bond. $\beta$-Scissions from RC1 radicals lead to ethylene and cyclohexyl radicals, which produce by opening of the cycle ethyl radicals and 1,3-butadiene, a major product of this study as shown in Figure 2. RC2 radicals react by breaking a $\mathrm{C}-\mathrm{C}$ bond with opening of the cycle, yielding resonancestabilized radicals, which isomerize and then decompose to give propyl radicals, a source of propene, and 1,3-pentadiene (see Figure 5). $\beta$-Scissions from RC3 radicals produce methylenecyclohexane, which is an important product of our study as shown in Figure 6 . $\beta$-Scissions from RC4 radicals lead to ethyl radicals and cyclohexene, which is a source of 1,3-cyclohexadiene and then of benzene. The rate constant of the $\beta$-scission from RC4 radicals yielding ethyl radicals and cyclohexene has been estimated in the JetSurF 1.1 mechanism (44) as that of 2-methyl-pent-4-yl radicals, while Sirjean et al. (53) has shown that the $\beta$-scission involving formation of a double bond inside the cycle have an activation energy about $7 \mathrm{kcal} / \mathrm{mol}$ larger than for acyclic radicals. That certainly explains the large overprediction observed for cyclohexene, as shown in Figure 5. 1,3-Cyclohexadiene is mostly obtained by $\mathrm{H}$ abstractions from cyclohexene followed by reaction with an oxygen molecule to give $\mathrm{HO}_{2}$ radicals and this diene. Benzene was mostly obtained by $\mathrm{H}$ abstractions from 1,3-cyclohexadiene followed by $\mathrm{C}-\mathrm{H}$ bond breaking. The rate constant used in the JetSurF 1.1 mechanism (44) for formation of 1,3-cyclohexadiene by reaction with $\mathrm{O}_{2}\left(\mathrm{k}=1 \times 10^{-11} \mathrm{~cm}^{3} \cdot \mathrm{mol}^{-1} \cdot \mathrm{s}^{-1}\right)$ is about 400 times 
faster at $800 \mathrm{~K}$ than the rate constant proposed by Touchard et al. (54) $\left(\mathrm{k}=3.2 \times 10^{12} \exp (-7650 / \mathrm{T})\right.$ $\left.\mathrm{cm}^{3} \cdot \mathrm{mol}^{-1} \cdot \mathrm{s}^{-1}\right)$. That certainly explains why formation of 1,3 -cyclohexadiene is correctly predicted, while cyclohexene is overpredicted, and the simulated formation of benzene is favored in lean mixture, while it is not the case experimentally (see Figure 7). Breaking of a $\mathrm{C}-\mathrm{C}$ bond with opening of the cycle of RC5 radicals is a source of 1-butene, an important reaction product above $800 \mathrm{~K}$. $\beta$ Scissions from RC6 radicals produce radicals which readily isomerize to give resonance-stabilized radicals, which decompose yielding 1,3-butadiene and 2-butyl radicals. Note that a significant part (about $20 \%$ ) of RC6 radicals also isomerizes to RC2 radicals.

RC1 and RC2 radicals could also react with an oxygen molecule to produce $\mathrm{HO}_{2}$ radicals and vinylcyclohexane, a minor product of this study (see Figure 6). RC3 and RC2 radicals could also react with an oxygen molecule to produce $\mathrm{HO}_{2}$ radicals and ethylidenecyclohexane, which has not been observed but could be the source of the ethylidenecylohexenes, the mole fraction profiles of which are displayed in Figure 6. RC3, RC4, RC5, and RC6 radicals could also react with an oxygen molecule to produce $\mathrm{HO}_{2}$ radicals and the different isomers of ethylcyclohexenes. Via formation of ethylcyclohexadienes, these species are certainly a good source of ethylbenzene and then styrene. This series of reactions leading to aromatic compounds can be important even at low temperature, which explains why a noticeable formation of ethylbenzene and styrene has been observed below $800 \mathrm{~K}$ as shown in Figure 7. These reactions are shown with dotted arrows in Figure 14, because formation of cyclic $\mathrm{C}_{8} \mathrm{H}_{14}$ species is not considered in the JetSurF 1.1 mechanism (44). Flow rate analysis shows that within the present model ethylcyclohexyl radicals also react with oxygen molecules to give a globalized radical which at $850 \mathrm{~K}$ mostly decomposes to give cyclohexane, ethylene, and $\mathrm{HO}_{2}$ radicals. These reactions have an important flow rate in the case of RC1, RC5, and RC6 radicals.

\section{- Possible Ways of Reactions Important below $800 \mathrm{~K}$}

According to Walker and Morley (55), cyclohexane reacts at low temperature following the same pathway as that proposed for alkanes and shown in Figure 14. Alkyl radicals $\mathrm{R} \bullet$ are produced by $\mathrm{H}$ abstractions and add thereafter to $\mathrm{O}_{2}$ and yield peroxy radicals ROO•. Some consecutive steps will then lead to formation of hydroperoxides, which are degenerate branching agents explaining the high reactivity of the alkanes at low temperature. When the temperature increases, the equilibrium $\mathrm{R} \bullet+\mathrm{O}_{2}=\mathrm{ROO} \bullet$ begins to be displaced back to the reactants and formation of ROO $\bullet$ radicals is less favored. The larger concentration of $\mathrm{R} \bullet$ radicals increases the rate of the strongly inhibiting oxidation reaction $\mathrm{R} \bullet+\mathrm{O}_{2}=\bullet \mathrm{HO}_{2}+$ conjugated olefin. Furthermore, unimolecular reaction channels from - $\mathrm{QOOH}$ radicals become important and lead to formation of cyclic ethers, ketones, or conjugated olefins

Considering that the same scheme can be applied to alkylcyclohexanes, Figure 15 presents the ways of formation which can be envisaged to explain formation of the main products observed in this study below $800 \mathrm{~K}$. At higher temperatures ethylcyclohexane is consumed by $\mathrm{H}$ abstractions to form the six cyclohexylethyl radicals previously described. In the lower part of the temperature range studied cyclohexylethyl radicals react mainly by addition to oxygen molecules to produce 6 cyclohexylethylperoxy radicals (shown in Figure 15 only for RC3 and RC4 radicals). These 6 cyclohexylethylperoxy radicals can lead to a large number of hydroperoxy radicals via isomerization by internal transfer of a $\mathrm{H}$ atom. Figure 15 presents only the hydroperoxy radicals leading to compounds which have been experimentally observed. 


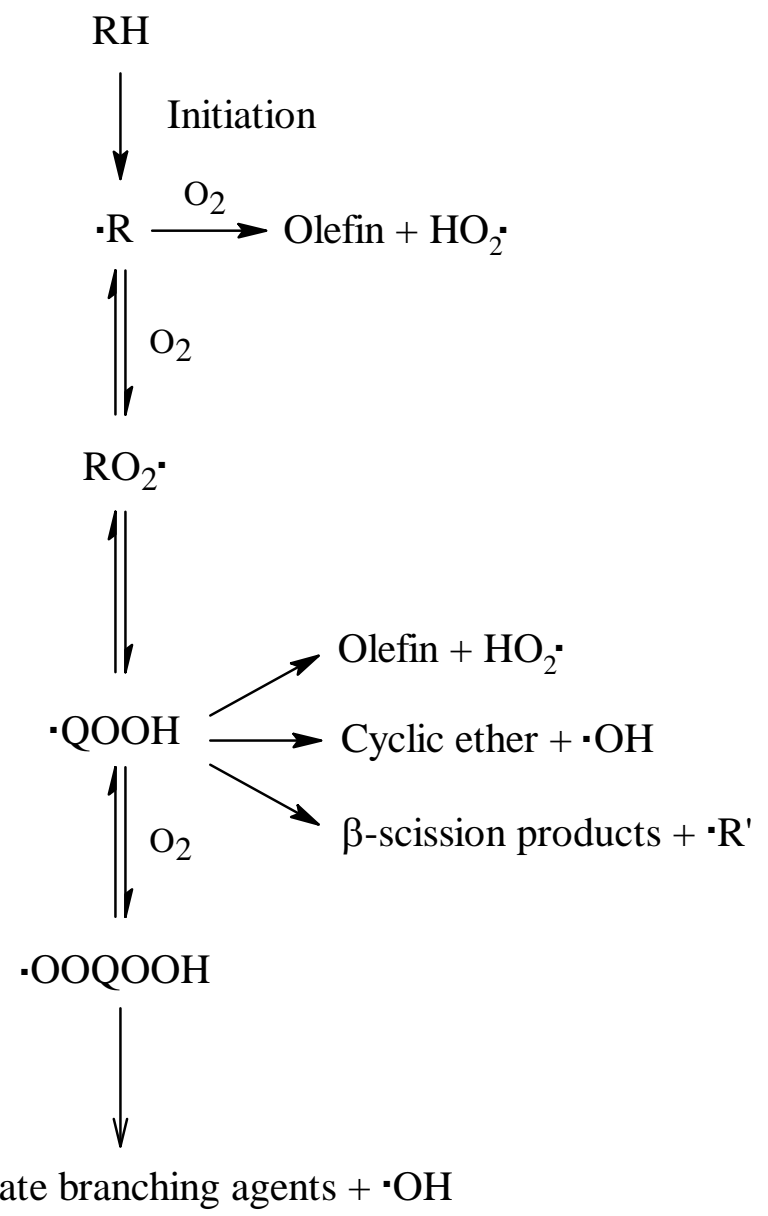

Figure 14. General scheme of low-temperature oxidation of an alkane (RH).

Note that the observed intermediates show that isomerizations by transfer of a tertiary $\mathrm{H}$ atom, which require a lower activation energy for the same ring strain energy in the bicyclic transition state, are favored. This type of isomerization occurs in the case the peroxy radicals deriving from $\mathrm{RC6}, \mathrm{RC5}, \mathrm{RC4}$, and RC2 radicals, and decomposition of the obtained hydroperoxy radicals lead to $\mathrm{OH}$ radicals and 1-methyl,7-oxabicyclo[2.2.1]heptane, oct-7-en-3-one, 1-ethyl,7oxabicyclo[4.1.0]heptane, and 3-methyl,2-oxaspiro[1,5]octane, respectively. Octenone is obtained by decomposition of a four-membered ring cyclic ether, according to what has been shown by Walker and Morley (55) in the case of cyclohexane: the bicyclic ether with an additional ring involving 4 members is very unstable and decomposes very quickly to 1-hexenal. Figure 16 presents this pericyclic reaction in the case of the cyclic ether, leading to formation of octenone. Note that branched unsaturated $\mathrm{C}_{8}$ aldehyde, which has not been experimentally observed, could also be a possible product. Analysis of this reaction for all possible bicyclic ethers with an additional ring involving 4 members deriving from ethylcyclohexane shows that this channel is the only one leading to an acyclic ketone: all other ones lead either to $\mathrm{C}_{8}$ aldehydes, to cyclohexanone and ethylene, or to smaller aldehydes and alkenes. 


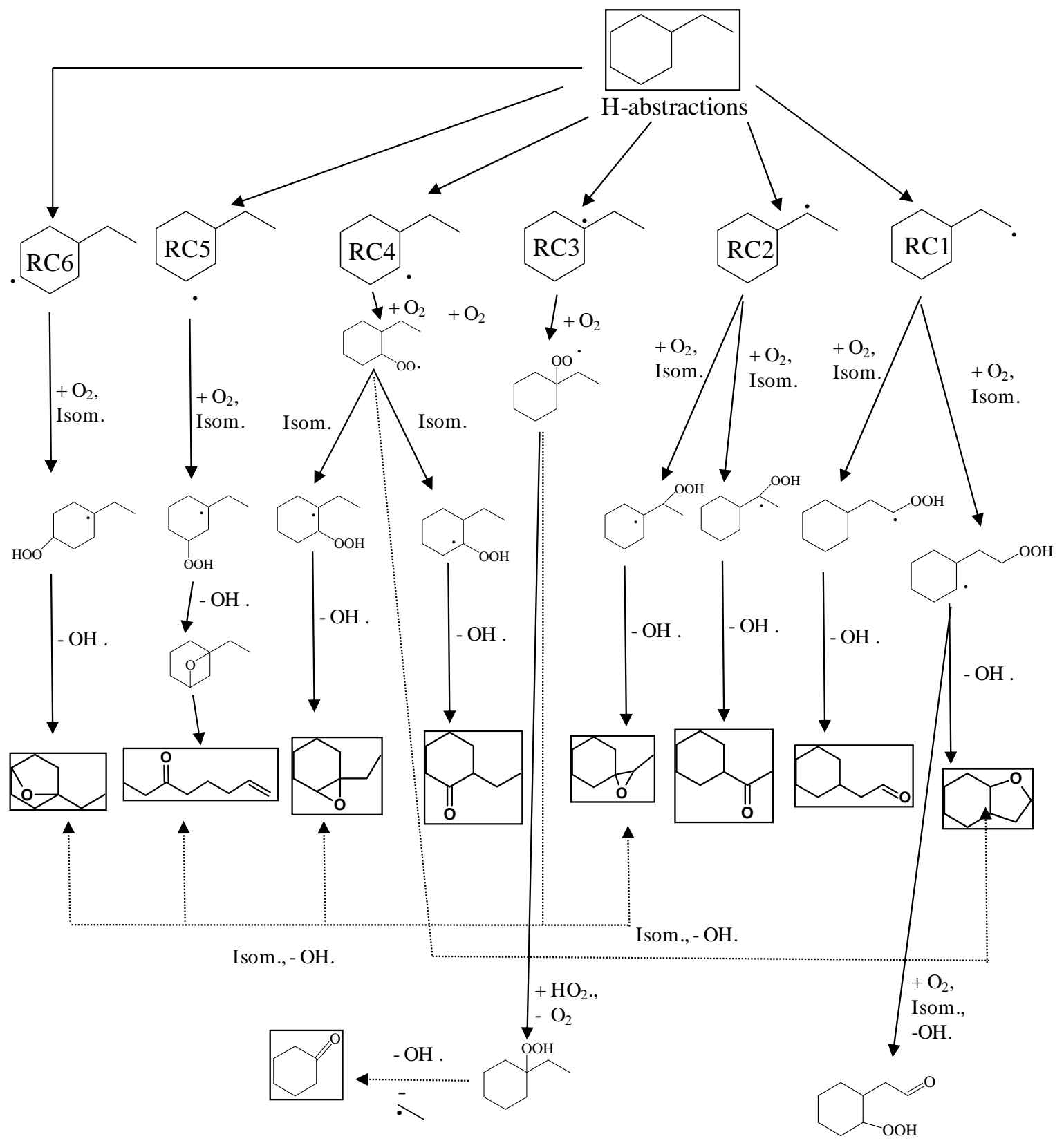

Figure 15. Ways of formation which can be envisaged to explain formation of the main products observed in this study below $800 \mathrm{~K}$.

Other types of isomerisations which are favored are those abstracting a $\mathrm{H}$ atom from an atom of carbon also carrying a $\mathrm{O}$ atom. As four-membered ring isomerizations require a high strain energy, these isomerisations do not occur directly but certainly in two steps. The first step is formation of a hydroperoxy radical though abstraction a $\mathrm{H}$ atom from an atom of carbon not carrying any $\mathrm{O}$ atom. The second step is isomerization abstracting this time a $\mathrm{H}$ atom from the atom of carbon also carrying a $\mathrm{O}$ atom. This type of isomerization requires a lower activation energy for the same ring strain energy of the transition state and the same type of abstracted $\mathrm{H}$ atom. This is the case of peroxy radicals deriving from $\mathrm{RC} 4, \mathrm{RC} 2$, and $\mathrm{RC} 1$ radicals, with production of $\mathrm{OH}$ radicals and 2-ethylcyclohexanone, cyclohexylmethylketone, and 2-cyclohexylacetaldehyde, respectively. The only product which does not derive from the two previously described types of isomerisations is 7oxabicyclo[4.3.0]nonane. This product can be obtained from hydroperoxy radicals deriving from RC4 
and RC1 radicals. The channel deriving from RC1 radicals is certainly favored as it involves transfer of 4 secondary $\mathrm{H}$ atoms, instead of 3 primary ones in the case of the channel deriving from RC4 radicals. In both cases, the transition state involves formation of a new seven-membered ring, outside from the cyclohexyl cycle. In this case no additional strain energy is due to formation of the bicycle.

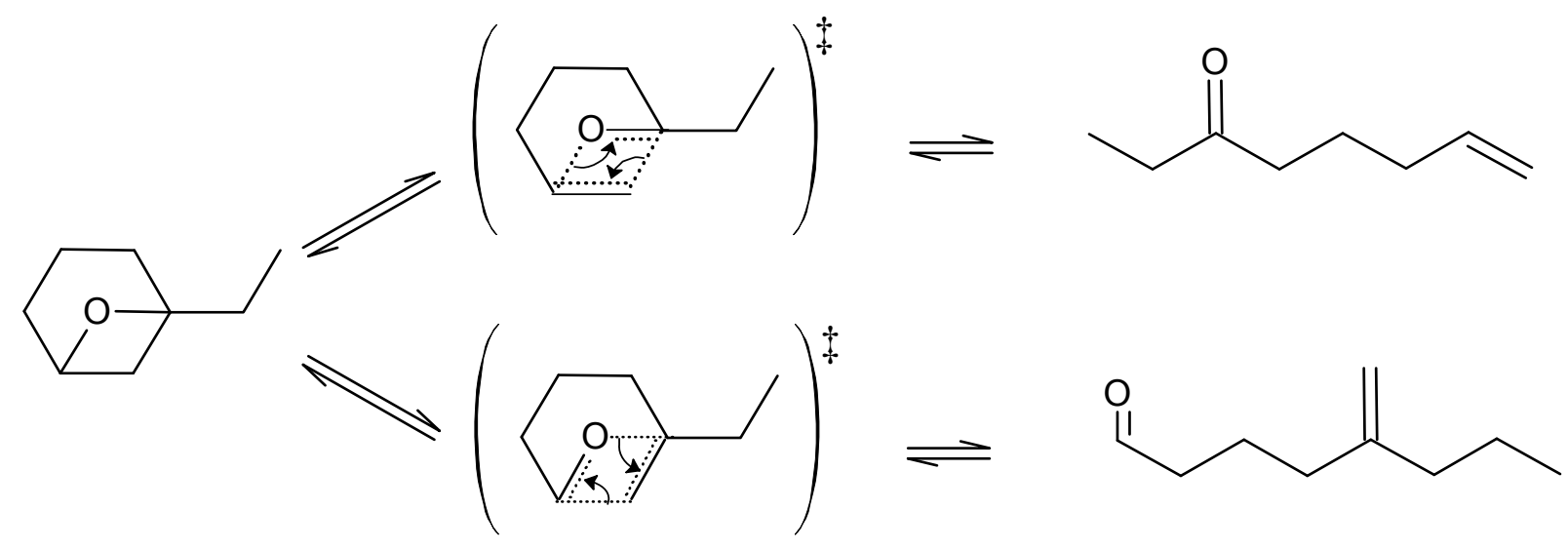

Figure 16. Mechanism of the pericyclic reaction leading to octenone.

In addition to decomposition to cyclic ethers, aldehydes, or ketone, the hydroperoxy radicals can also add a second time to an oxygen molecule to form radicals which in their turn isomerize and decompose to form ketohydroperoxides. An example of formation of a ketohydroperoxide from RC1 is shown in Figure 15. Ketohydroperoxides, which are responsible for the high reactivity observed from $600 \mathrm{~K}$, easily decompose and are certainly the source of the $C_{2}-C_{5}$ aldehydes and ketones observed.

Cyclohexylethylperoxy radicals can also react with $\mathrm{HO}_{2}$ radicals to yield cyclohexylethylhydroperoxides. Such a channel is displayed for the peroxy radicals deriving from RC3 radicals. In this case decomposition of the obtained cyclohexylethylhydroperoxide can easily lead to formation of cyclohexanone, an important product of this study as shown in Figure 4.

\section{Conclusion}

A study of the oxidation of ethylcyclohexane has been performed in a jet-stirred reactor under quasiatmospheric pressure, at a residence time of $2 \mathrm{~s}$, at temperatures ranging from 500 to $1100 \mathrm{~K}$, for three equivalence ratios $(0.25,1$, and 2$)$, and a fuel mole fraction of 0.005 . A high reactivity has been observed at temperature below $650 \mathrm{~K}$ with a marked NTC behavior. The low-temperature reactivity is lower than that of $\mathrm{n}$-octane but close to that of 1-octene. A wide range of products has been identified both below and above the NTC zone, showing a high complexity of the involved chemistry. Formation of all the observed products can be qualitatively explained using reactions pathways directly derived from those usually proposed for oxidation of acyclic alkanes (55). Reactions of all isomers of cyclohexylethyl radicals have to be considered carefully, with no obvious a priori simplification. A noticeable formation of aromatic species (ethylbenzene and styrene) can be observed at temperatures as low as $600 \mathrm{~K}$.

Better knowledge of the chemistry of the oxidation of alkylcyclohexanes will require development of a complete low-temperature mechanism in order to model the present results but also to extend the experimental methodology described here to study compounds with a longer alkyl chain such as $n$-butylcyclohexane or $n$-hexylcyclohexane. 


\section{Supporting Information}

Mass spectra of compounds of mass 126 are given as well as a table of full experimental data. This material is available free of charge via the Internet at http://pubs.acs.org.bases-doc.univ-lorraine.fr.

\section{Acknowledgment}

This study was supported by SAUDI ARAMCO.

\section{References}

1. Hostettler, F. D.; Kvenvolden, K. A. Environ. Forensics 2002, 3, 293-301

2. Guibet, J. C. Fuels and Engine; Publications de I'Institut Fransais de Petrole, ed.s Technip: Paris, 1999.

3. Pitz, W. J.; Mueller, C. J. Prog. Energy Combust. Sci. 2011, 37, 330- 350

4. Ranzi, E.; Faravelli, T.; Gaffuri, P.; Sogaro, A. Combust. Flame 1995, 102, 179- 192

5. Curran, H. J.; Gaffuri, P.; Pitz, W. J.; Westbrook, C. K. Combust. Flame 1998, 114, 149- 177

6. Biet, J.; Hakka, M. H.; Warth, V.; Glaude, P. A.; Battin-Leclerc, F. Energy Fuels 2008, 22, 22582269

7. Westbrook, C. K.; Pitz, W. J.; Herbinet, O.; Curran, H. J.; Silke, E. J. Combust. Flame 2009, 156, 181- 199

8. Dagaut, P.; Ristori, A.; El Bakali, A.; Cathonnet, M. Fuel 2002, 81, 173- 184

9. Ribaucour, M.; Roubaud, A.; Minetti, R.; Sochet, L. R. Proc. Combust. Inst. 2000, 28, 1701- 1707

10. Dievart, P.; Dagaut, P. Proc. Combust. Inst. 2011, 33, 209- 216

11. Zeelenberg, A. P.; De Bruijn, H. W. Combust. Flame 1965, 9, 281- 295

12. Bonner, B. H.; Tipper, C. F. H. Combust. Flame 1965, 3, 17- 327

13. Gulati, S. K.; Walker, R. W. J. Chem. Soc., Faraday Trans. 2 1989, 85, 1799- 1812

14. Klai, S. E.; Baronnet, F. J. Chim. Phys. 1993, 90, 1929- 1950

15. Klai, S. E.; Baronnet, F. J. Chim. Phys. 1993, 90, 1951- 1998

16. Voisin, D.; Marchal, A.; Reuillon, M.; Boettner, J. C.; Cathonnet, M. Combust. Sci. Technol. 1998, 138, 117- 133

17. El Bakali, A.; Braun-Unkhoff, M.; Dagaut, P.; Frank, P.; Cathonnet, M. Proc. Combust. Inst. 2000, $28,1631-1638$

18. Lemaire, O.; Ribaucour, M.; Carlier, M.; Minetti, R. Combust. Flame 2001, 127, 1971- 1980

19. Tanaka, S.; Ayala, F.; Keck, J. C.; Heywood, J. B. Combust. Flame 2003, 132, 219- 239

20. Sirjean, B.; Buda, F.; Hakka, H.; Glaude, P. A.; Fournet, R.; Warth, V.; Battin-Leclerc, F.; RuizLopez, M. F. Proc. Combust. Inst. 2007, 31, 277- 284

21. Daley, E.; Berkowitz, A. M.; Oehlschlaeger, M. A. Int. J. Chem. Kinet. 2008, 40, 624- 634

22. Hong, Z.; Lam, K.-Y.; Davidson, D. F.; Hanson, R. K. Combust. Flame 2011, 158, 1456- 1468

23. Bennett, P. J.; Gregory, D.; Jackson, R. A. Combust. Sci. Technol. 1996, 115, 83- 103

24. Yang, Y.; Boehman, A. L. Proc. Combust. Inst. 2009, 32, 419- 426

25. Law, M. E.; Westmoreland, P. R.; Cool, T. A.; Wang, J.; Hansen, N.; Taatjes, C. A.; Kasper, T. Proc. Combust. Inst. 2007, 31, 565- 573

26. Ciajolo, A.; Tregrossi, A.; Mallardo, M.; Faravelli, T.; Ranzi, E. Proc. Combust. Inst. 2009, 32, 595591

27. Ji, C.; Dames, E.; Sirjean, B.; Wang, H.; Egolfopoulos, F. Proc. Combust. Inst. 2011, 33, 971- 978

28. Wu, F.; Kelley, A. P.; Law, C. K. Combust. Flame 2012, 159, 1417-1425

29. McEnally, C. S.; Pfefferle, L. D. Combust. Flame 2004, 136, 155- 167

30. Zeppieri, S.; Brezinski, K.; Glassman, I. Combust. Flame 1997, 108, 266- 286

31. Pitz, W. J.; Naik, C. V.; Mhaolduin, T. N.; Westbrook, C. K.; Curran, H. J.; Orme, J. P.; Simmie, J. M. Proc. Combust. Inst. 2007, 31, 267- 275

32. Orme, J. P.; Curran, H.; Simmie, J. J. Phys. Chem. A 2006, 110, 114- 131 
33. Vasu, S. S.; Davidson, D. F.; Hong, Z.; Hanson, R. K. Energy Fuels 2009, 23, 175- 185

34. Vasu, S. S.; Davidson, D. F.; Hanson, R. K. Combust. Flame 2009, 156, 736- 749

35. Vanderover, J.; Oehlschlaeger, M. Int. J. Chem. Kinet. 2009, 41, 82- 91

36. Skeen, S. A.; Yang, B.; Jasper, A. W.; Pitz, W. J.; Hansen, N. Energy Fuels 2012, in press.

37. Bales-Gueret, C.; Cathonnet, M.; Boettner, J. C.; Gaillard, F. Energy Fuels 1992, 6, 189-194

38. Ristori, A.; Dagaut, P.; El Bakali, A.; Cathonnet, M. Combust. Sci. Technol. 2001, 165, 1997- 228

39. Dagaut, P.; El Bakali, A.; Ristori, A. Fuel 2006, 85, 944- 956

40. Mati, K.; Ristori, A.; Gaïl, S.; Pengloan, G.; Dagaut, P. Proc. Combust. Inst. 2007, 31, 2939- 2946

41. Crochet, M.; Minetti, R.; Ribaucour, M.; Vanhove, G. Combust. Flame 2010, 157, 2078- 2085

42. Pousse, E.; Porter, R.; Warth, V.; Glaude, P. A.; Fournet, R.; Battin-Leclerc, F. Combust. Flame 2010, 157, 75- 90

43. Natelson, R. H.; Kurman, M. S.; Cernanski, N. P.; Miller, D. L. Combust. Flame 2011, 158, 23252337

44. Wang, H.; Dames, E.; Sirjean, B.; Sheen, D. A.; Tangko, R.; Lai, J. Y. W.; Violi, A.; Egolfopoulos, F. N.; Davidson, D. F.; Hanson, R. K.; JetSurF, version 2; Sept 19, 2010; http://melchior.usc.edu/JetSurF/JetSurF1.1.

45. Matras, D.; Villermaux, J. Chem. Eng. Sci. 1973, 28, 129- 137

46. David, R.; Matras, D. Can. J. Chem. Eng. 1975, 53, 297- 300

47. Hakka, M. H.; Glaude, P. A.; Herbinet, O.; Battin-Leclerc, F. Combust. Flame 2009, 156, 21292144

48. Herbinet, O.; Battin-Leclerc, F.; Bax, S.; Le Gall, H.; Glaude, P. A.; Fournet, R.; Zhou, Z.; Deng, L.; Guo, H.; Xie, M.; Qi, F. Phys. Chem. Chem. Phys. 2011, 13, 296- 308

49. Herbinet, O.; Husson, B.; Cord, M.; Fournet, R.; Glaude, P. A.; Sirjean, B.; Battin-Leclerc, F.; Wang, Z.; Xie, M.; Cheng, Z.; Qi, F. Combust. Flame 2012, in press.

50. Porter, R.; Glaude, P. A.; Buda, F.; Battin-Leclerc, F. Energy Fuels 2008, 22, 3736-3743

51. Tranchant, J. Manuel pratique de chromatographie en phase gazeuse; Masson: Paris, France, 1995.

52. Herbinet, O.; Bax, S.; Glaude, P. A.; Carré, V.; Battin-Leclerc, F. Fuel 2011, 90, 528- 535

53. Sirjean, B.; Glaude, P. A.; Ruiz-Lòpez, M. F.; Fournet, R. J. Phys. Chem. A 2008, 112, 1159811610

54. Touchard, S.; Fournet, R.; Glaude, P. A.; Warth, V.; Battin-Leclerc, F.; Vanhove, G.; Ribaucour, M.; Minetti., R. Proc. Combust. Inst. 2005, 30, 1073- 1081

55. Walker, R. W.; Morley, C.Oxidation kinetics and autoignition of hydrocarbons. In Comprehensive Chemical Kinetics; Pilling, M., Ed.; Elsevier: New York, 1997; Vol. 35. 